\title{
Signal peptide peptidase and SPP-like proteases - possible therapeutic targets?
}

\author{
Torben Mentrup ${ }^{1}$, Ann-Christine Loock ${ }^{1}$, Regina Fluhrer ${ }^{2,3}$ and Bernd Schröder ${ }^{1}$
}

\author{
${ }^{1}$ Biochemical Institute, Christian Albrechts University of Kiel, Otto-Hahn-Platz 9, D-24118 Kiel, \\ Germany \\ ${ }^{2}$ Biomedizinisches Centrum (BMC), Ludwig Maximilians University of Munich, Feodor-Lynen- \\ Strasse 17, D-81377 Munich, Germany \\ ${ }^{3}$ DZNE - German Center for Neurodegenerative Diseases, Munich, Feodor-Lynen-Strasse 17, D- \\ 81377 Munich, Germany
}

To whom correspondence should be addressed: Dr. Bernd Schröder, MD, PhD, Biochemical Institute, Christian Albrechts University of Kiel, Otto-Hahn-Platz 9, D-24118 Kiel, Germany; Phone: +49-4318802218; Fax: +49-431-8802238; E-mail: baschroeder@biochem.uni-kiel.de 


\section{ABSTRACT}

Signal peptide peptidase (SPP) and the four homologous SPP-like proteases SPPL2a, SPPL2b, SPPL2c and SPPL3 are GxGD-type intramembrane-cleaving proteases (I-CLIPs). In addition to divergent subcellular localisations, distinct differences in the mechanistic properties and substrate requirements of individual family members have been unravelled. SPP/SPPL proteases employ a catalytic mechanism related to that of the $\gamma$-secretase complex. Nevertheless, differential targeting of SPP/SPPL proteases and $\gamma$-secretase by inhibitors has been demonstrated. Furthermore, also within the SPP/SPPL family significant differences in the sensitivity to currently available inhibitory compounds have been reported. Though far from complete, our knowledge on pathophysiological functions of SPP/SPPL proteases, in particular based on studies in mice, has been significantly increased over the last years. Based on this, inhibition of distinct SPP/SPPL proteases has been proposed as a novel therapeutic concept e.g. for the treatment of autoimmunity and viral or protozoal infections, as we will discuss in this review.

\section{KEYWORDS}

Intramembrane Proteolysis; Signal peptide peptidase; SPPL proteases; ERAD; $\gamma$-secretase; Autoimmunity 


\section{Introduction}

The genes encoding signal peptide peptidase (SPP) and the related signal peptide peptidaselike (SPPL) proteases were identified in a bioinformatic screen searching for homologues of the presenilins $[1,2]$, the catalytically active subunit of the $\gamma$-secretase complex. In parallel, characterisation of a proteolytic activity processing signal peptides after their liberation from nascent proteins in the endoplasmic reticulum (ER) identified SPP as the responsible protease by biochemical approaches, followed by computational identification of its homologues [3]. SPP/SPPL proteases and presenilins are multi-pass transmembrane proteins with 9 predicted transmembrane domains (TMDs) that share conserved (Y/F)D, GxGD and PAL motives which constitute their catalytic center (Fig. 1) [3-7]. These signature motives localise to TMD 6, 7 and 9, respectively. Mutation of either aspartic residue inactivates these aspartyl intramembrane proteases that are also referred to as GxGD proteases [8, 9]. The GxGD protease family is completed by the more distantly related bacterial type IV prepilins (TFPPs) and the archeal pre-flagellin peptidases (PFPs) $[10,11]$. In humans, seven GxGD proteases have been identified. These include the two presenilins, Presenilin 1 and Presenilin 2, and five members of the SPP/SPPL family: SPP, SPPL2a, SPPL2b, SPPL2c and SPPL3. These GxGD proteases are conserved in many other eukaryotes like fungi, protozoa, plants and animals. However, the number of paralogues differs between individual species. While mammals encode five members of the SPP/SPPL family, zebrafish, for instance, only exhibits three SPP/SPPL proteases with the SPPL2a/b/c subfamily being represented by a single SPPL2 protease [12]. In Drosophila melanogaster, this subfamily is even lacking completely and solely genes encoding orthologues of human SPP and SPPL3 are found. In Plasmodium falciparum, the protozoan parasite causing Malaria, only one SPP orthologue is detectable [12]. In contrast, plants possess a much more diverse set of SPP/SPPLs than mammals [13], 
indicating that the individual members have adopted here more distinct functions, possibly some of them being unique for plant cells and not-conserved in mammalian cells.

SPP/SPPL proteases are most likely catalytically active as monomers or homomeric dimers / multimers, since exogenous expression of these enzymes significantly increases their proteolytic capacity [4-6, 14-16]. In contrast exogenous expression of presenilins results in replacement of the endogenous proteins and only minor increase of catalytic activity, because presenilins require the formation of a high molecular weight complex with Aph-1 (anterior pharynx defective 1), Pen-2 (presenilin enhancer 2) and Nicastrin, to provide catalytic activity [17]. During formation of this $\gamma$-secretase complex in the ER the respective presenilin is autocatalytically endoproteolysed within its large hydrophilic loop between TMD 6 and TMD 7 [18]. This loop most likely constitutes a steric hindrance for substrate entrance of the substrate to the catalytic site. Since correct assembly of the $\gamma$-secretase complex seems to be a prerequisite for presenilin autoproteolysis, this may result in a structural change in the presenilin molecule that induces this process. While the hydrophilic loop between TMD 6 and TMD 7 of the presenilins is cytosolic, the corresponding loop in SPP/SPPL proteases is directed towards the lumen/ extracellular space and is comparably short [19]. Thus, it may not interfere with the catalytic centre, making the SPP/SPPL proteases independent of the constraint to form a complex and get endoproteolysed. The altered orientation of the loop between TMD 6 and TMD 7 reflects an overall inverted topology of SPP/SPPL proteases compared to presenilins. While the N-termini of SPP/SPPL proteases face the luminal/extracellular space, the C-termini are directed towards the cytosol [19]. This difference in topology might also account for the opposing substrate preferences of the two protease families: While presenilins seem to exclusively accept substrates with transmembrane domains in type I orientation ( $\mathrm{N}_{\text {out }}$ ), all SPP/SPPL substrates identified so far comprise transmembrane domains with type II orientation $\left(\mathrm{N}_{\text {in }}\right)$ [3, 19-23]. 
The $\gamma$-secretase complex as well as several SPP/SPPL proteases participate in a twostep proteolytic process, termed regulated intramembrane proteolysis (RIP) [24]. In the first step of RIP, either the ectodomain/luminal domain of a single-pass transmembrane protein is liberated (shedding) or a loop between two adjacent TMDs of a multi-pass transmembrane protein is cut. As a result, protein fragments with rather short extracellular/luminal domains, which are still integral to the membrane, are generated. The second step of RIP is catalysed by intramembrane proteases that hydrolyse peptide bonds within or close the extracellular border of the TMD as illustrated in Fig. 1. This cleavage results in the liberation of an extracellular/ luminal peptide and an intracellular peptide (ICD) that is released to the cytosol [24]. Like presenilins, SPP and SPPL2b strictly depend on substrates with a short ectodomain and, thus, either on the first step of RIP or on substrates that naturally occur with short ectodomains [14, 25-28]. As suggested by the analysis of CD74 processing [16, 29], SPPL2a most likely exhibits similar requirements regarding the length of the substrate ectodomain as SPPL2b, though this specific aspect has not been investigated as systematically as for SPPL2b [14]. Surprisingly, SPPL3 accepts substrates independent of their ectodomain length and is capable of acting like a sheddase in the RIP cascade [6, 30, 31], which in principle enables it to generate bona fide substrates for other intramembrane proteases. However, this, until now, has only been demonstrated for a viral substrate, the foamy virus envelope protein (FVenv) [6] and not for cellular SPPL3 substrates. Cleavage of substrates with rather long ectodomains by SPPL3 is a unique characteristic of an intramembrane aspartyl protease, and has only been attributed to rhomboids, which are intramembrane serine proteases [32]. However, SPPL2c remains an orphan protease and since no substrates have been identified, its substrate requirements currently remain elusive.

Presenilins and SPPL2b utilise multiple cleavages within the TMDs of their substrates to release the products from the membrane $[4,33,34]$. Starting from the C-terminal end of the 
substrates TMD, these proteases release their first cleavage product with an initial cut and proceed in a consecutive manner towards the N-terminal end of the substrates TMD until the remaining hydrophobic sequence is short enough to detach from the membrane releasing the second cleavage product [35]. However, neither the initial cleavage nor the consecutive cleavages of these intramembrane proteases are precise, resulting in cleavage products with variable $\mathrm{N}$ - and $\mathrm{C}$-termini, respectively [4, 34]. In addition, the processivity and cleavage pattern of these proteases can be modulated by certain mutations as well as chemical compounds $[18,33,36]$ and even the lipid environment as demonstrated for the presenilins [37]. To what extent the lipid environment impacts on substrate processing by SPP/SPPL proteases and whether SPPL3 and SPPL2c apply a similar cleavage mechanism to process their substrates remains to be investigated.

In line with the multiple cleavage sites, GxGD proteases do not recognise a consensus site based on the primary structure of the substrate, but rather depend on secondary structure elements within the substrates TMDs and juxtamembrane domains [14, 16, 26, 38-41]. Helixdestabilizing residues and polar residues like serine and cysteine residues in the substrate's TMD promote cleavage by SPP, SPPL2a and SPPL2b [16, 38, 42, 43]. In addition, SPPL2a and SPPL2b seem to require certain determinants within the juxtamembrane domains of their substrates for efficient recognition $[14,16]$. Palmitoylation of cytosolic, membrane-proximal cysteine residues may influence access of the substrate to the intramembrane protease and/or to alternative degradation pathways, however, this does not seem to be a prerequisite for cleavage by SPPL2a/b per se $[16,44]$. Currently these conclusions are based on a few studies on single enzyme/substrate combinations. For a general perspective and to allow computerbased substrate predictions, intensive further studies on many more enzyme/substrate combinations are required. 
Other than the two presenilins, which embedded in $\gamma$-secretase complexes mainly localise to the cell surface and later secretory as well as endosomal compartments $[45,46]$, the subcellular localisations of the individual SPP/SPPL proteases differ significantly. While SPP and SPPL2c localise to the ER, SPPL3 resides in the Golgi [47]. SPPL2a is transported to late endosomes/lysosomes and SPPL2b is located the plasma membrane [47, 48]. SPP contains a KKXX motif close to its C-terminus [3] presumably involved in mediating ER retention of this protease. However, this has not yet been confirmed experimentally. Lysosomal targeting of SPPL2a critically depends on a canonical C-terminal tyrosine-based sorting signal as documented by a mislocalisation of respective mutants [48]. How sorting of the other SPP/SPPL family members is controlled remains to be investigated.

To date, only a limited number of substrates cleaved by SPP/SPPL proteases have been identified. These were comprehensively compiled and listed in a recent review [23]. In many cases, the characterisation and validation of the identified cleavage events is limited to cell-based experimental systems. Thus, it remains to be confirmed to what extent processing of these substrates plays a role under endogenous conditions in vivo and if this fulfils any regulatory downstream function. Since this review aims at discussing the potential of SPP/SPPL proteases as pharmacological targets, we will here specifically highlight those substrates and protease functions which have been clearly linked with (patho)-physiologically relevant processes and/or observed phenotypes in model organisms. In addition, potential, not yet explored connections between primarily in vitro characterised substrates and physiological pathways will be discussed where appropriate. 


\section{Known physiological functions of SPP/SPPL proteases}

Different model organisms ranging from $C$. elegans to mice, have been employed to study loss-of-function phenotypes of SPP/SPPL proteases. As mentioned, the number of SPP/SPPL family members is significantly lower in non-mammalian and non-vertebrate organisms, becoming especially evident in a reduced complexity or even entire absence of the SPPL2 subfamily. Therefore, in particular for these three proteases mice may represent a more valid experimental system in order to draw conclusions about functions of the human SPP/SPPL orthologues and the therapeutic potential of their inhibition. Currently reported mouse models analysing the in vivo functions of SPP/SPPL proteases are summarised in Table 1.

\section{$\underline{2.1 \mathrm{SPP}}$}

As documented in its name, SPP was initially discovered for its ability to process signal peptides derived from several proteins [3,23]. It is still unclear whether all signal peptides can be cleaved by SPP and this protease represents the universal clearance for these fragments or whether this acts in conjunction with other degradative pathways and only selected signal peptides are cleaved by SPP. Beyond signal peptides, recent discoveries have significantly enhanced our knowledge of SPP functions [23]. This includes the identification of selected ER-localised tail-anchored (TA) proteins like Heme oxygenase 1 (HO-1) as novel SPP substrates [28, 49]. Whether SPP cleavage of TA proteins fulfils primarily a degradative purpose to clear these proteins from the ER membrane or whether the liberated cleavage products exhibit biological functions may need to be individually addressed. In case of $\mathrm{HO}-1$, nuclear translocation of the released ICD has been observed [49]. In cancer cells, this fragment was found to enhance proliferation and migration [49]. SPP forms complexes with components of the ER-associated degradation (ERAD) pathway like the pseudoprotease 
Derlin-1 as well as the ubiquitin ligase TRC8 $[50,51]$. Mechanistically, SPP can modulate ERAD by cleaving the ERAD regulator X-box binding protein 1 (XBP1u) [50], which can inhibit the unfolded protein response (UPR)-inducing functions of its spliced isoform XBP1s. However, SPP may also actively participate in the ERAD process after associating with misfolded membrane proteins in large oligomeric complexes in the ER membrane [15]. In yeast, SPP was found to regulate cellular levels of several plasma membrane nutrient transporters as exemplified by the zinc transporter Zrt1 by inducing their degradation in the ER [52]. The model proposed by Avci et al. involves a direct proteolytic action of yeast SPP on these multi-pass membrane proteins finally enabling their clearance from the ER membrane. To what extent mammalian SPP can regulate cellular nutrient uptake in a similar way is currently unclear.

Though these diverse molecular functions of SPP have been primarily characterised in cultured cells, several knockdown or knockout studies in different model organisms have highlighted the importance of SPP. Depletion of SPP in C. elegans resulted in embryonic lethality and molting defects [53] Similarly, a SPP knockout in Drosophila was associated with impaired larval development and lethality [54]. In zebrafish, knockdown of SPP caused cell death in the nervous system [55] and in mice a constitutive knockout of this protease led to embryonic lethality after day $13.5 \mathrm{~d}$ [51], however without apparent histological abnormalities in the $S P P^{-/-}$mouse embryos [51].

In none of these models, it is known which of the described molecular functions of SPP are compromised and to what extent these contribute to the described phenotypes, in particular the embryonic lethality in mice. This could reflect the impairment of a specific pathway with a critical role in development like the defective Notch signalling in presenilindeficient mice $[56,57]$. Alternatively, a generalised failure to degrade signal peptides or a major dysregulation of the ERAD and UPR systems seems also conceivable. Interestingly, at 
the cellular level a constitutive knockout of SPP in the colorectal carcinoma cell line HCT116 was tolerated [28]. Apart from growing slightly slower and being less adherent, the cells appeared healthy. This indicates that at least in immortalised, continuously proliferating cell lines a loss of SPP and any potentially resulting proteostatic dysbalance can be compensated. Therefore, final conclusions which of the outlined SPP functions are really pathophysiologically relevant and which can be easily taken over by other pathways cannot be drawn yet. In particular, conditional approaches, which will allow to circumvent the embryonic lethality by generating a tissue-specific and/or inducible $S P P$ knockout in mice, should be helpful in this context.

\subsection{SPPL2a:}

In contrast to SPP, constitutive SPPL2a knockout mice are viable, fertile and not overtly compromised [29, 58, 59]. They exhibit a major immunological phenotype which has been independently observed and characterised in three different strains of SPPL2a-deficient mice which were generated by gene targeting [29] or derived from a $N$-ethyl- $N$-nitrosourea (ENU) mutagenesis screens $[58,59]$. All three models exhibited a characteristic B cell differentiation defect that manifests during the so-called transitional (T) stages of splenic B cell maturation which these cells have to pass through prior to becoming mature, antigen-reactive B cells. Whereas the $\mathrm{T} 1$ population was largely preserved in SPPL $2 a^{-/}$mice, T2 B cells as well as subsequent stages like the mature B cells were significantly depleted [29, 58, 59]. Importantly, in addition to this maturation block of the follicular B cells also innate-like B cell populations like the marginal zone and B1 B cells were significantly reduced in SPPL2adeficient mice $[29,58,59]$ so that these mice are characterised by a global depletion of $\mathrm{B}$ lymphocytes. Since also the remaining B cells exhibit a major functional deficit, antibody production and humoral immune responses are significantly impaired. In addition, SPPL $2 a^{-/-}$ 
mice exhibit a concomitant reduction of dendritic cells (DCs), primarily of the myeloid DCs whereas the plasmacytoid DCs were less or not affected depending on the model [58-60]. Both phenotypes reflect cell-intrinsic consequences of SPPL2a-deficiency which could be linked with the disrupted proteolysis of CD74, the invariant chain of the MHCII complex (MHCII). As its canonical function, the type II transmembrane protein CD74 mediates assembly and intracellular transport of MHCII [61]. In the antigen-processing compartments, the concerted action of several endosomal proteases degrades the luminal domain of CD74 thereby allowing peptide loading of MHCII [61]. Importantly, a membrane-bound CD74 NTF remains from this process which depends on SPPL2a for its removal from the membrane as demonstrated by a massive accumulation of this fragment in SPPL2a-deficient B cells and DCs [29, 58-60]. Upon SPPL2a-mediated proteolysis of CD74, a CD74 ICD is released into the cytosol which is capable of entering the nucleus [62-64]. Regulatory functions of this cleavage fragment, in particular in B cells, have been proposed $[62,65,66]$, however, have remained in part controversial with regard to a direct effect on the NFkB pathway [64]. Though it may not be completely excluded that the failure to release this cleavage fragment contributes to the described phenotypes of $S P P L 2 a^{-/}$in a minor way, the significant phenotype amelioration in SPPL2a-CD74 double-deficient mice highlighted the accumulation of the unprocessed CD74 NTF as the major underlying cause [29]. The biochemical role of SPPL2a in degrading the CD74 NTF is preserved in human B cells, which was documented in EBV-lymphoblastoid cell lines derived from patients with a genomic chromosomal microdeletion encompassing exon 1 of the SPPL2a as well as part of the neighbouring AP4E1 gene [67]. In the absence of any clinical information on the haematologic and immunological status of these patients the putative phenotype caused by a loss of SPPL2a in humans currently remains elusive. 
In addition to the described immunological phenotype, SPPL $2 a^{-/-}$mice exhibit an impaired mineralisation of their tooth enamel which is associated with a characteristic, macroscopically detectable tooth decolorisation [68]. As supported by distinct histological changes, this most likely reflects a failure of the enamel-producing cells, the ameloblasts, during the maturation stage where reabsorption of the organic enamel matrix needs to take place [68]. How this phenotype may be linked to any substrate or protease-independent function of SPPL2a is currently unclear. With regard to a potential therapeutic modulation of SPPL2a activity, the role of SPPL2a in tooth enamel production may not be too limiting since in humans this process is completed during childhood and does not continue throughout lifetime as in rodent incisors.

Based on a ubiquitous tissue expression of SPPL2a in mice [60], the identification of additional patho-physiologically relevant functions of this protease may be anticipated. Similarly, the in vivo relevance of several substrates that have been primarily characterised in cellular systems [23], often employing overexpression, will require further investigations. These include Tumor necrosis factor $\alpha$ (TNF) [4, 47], Fas ligand (FasL) [5] as well as the proteins ITM2B/Bri2 [69], TMEM106B [70] and Neuregulin 1 type III [71].

\subsection{SPPL2b:}

In contrast to SPPL2a, much less is known about the physiological functions of SPPL2b. In cell-based experimental systems utilising co-overexpression of substrates and proteases, both proteases exhibit significantly overlapping specificities and cleavage properties. This is also the case for the CD74 NTF which is efficiently cleaved by both SPPL2a and SPPL2b under these conditions [60]. However, in vivo depletion of SPPL2b does not influence the levels of this fragment [60]. Consequently, SPPL2b-deficient mice display no alterations in B cell 
development or function as observed in SPPL $2 a^{-/}$animals. Furthermore, combined ablation of SPPL2a/b does not aggravate the biochemical and physiological consequences observed in the SPPL2a single-deficient mice, arguing for at least partially non-redundant functions of both GxGD proteases in this cell type which is most likely caused by their differential subcellular distributions.

SPPL2a/b double-deficient mice are viable, without any overt disability and exhibit the phenotypic changes associated with the loss of SPPL2a (Table 1) [60]. However, so far no phenotypes specifically associated with SPPL2b deficiency have been described. As mentioned above, for many in vitro characterised substrates like TNF, Bri2 and Neuregulin it is not yet clear to what extent SPPL2a and SPPL2b contribute to these cleavage events under endogenous conditions in vivo. Furthermore, the functional consequences largely remain elusive to date. In the case of TNF, the proteolytically released ICD may undergo nuclear translocation $[47,64,72]$ and was proposed to influence expression of the cytokine IL-12 [47]. Consequently, inhibition of SPPL2a/b by (Z-LL)2-ketone or siRNA-mediated knockdown of these proteases reduced the IL-12 release of DCs upon stimulation by lipopolysaccharide. It remains to be examined how relevant this pathway is in response to a broader range of pathogenic stimuli as well as in the course of immune reactions in vivo and if the described effects on IL-12 secretion can be recapitulated in murine genetic models of SPPL2a/b deficiency.

Based on the high expression of SPPL2b in the central nervous system [60], in particular the physiological relevance of SPPL2b-dependent Bri2-processing will deserve further attention. Mutations in the Bri2 gene have been shown to be causative for amyloid deposition in familial British and Danish dementia [73, 74]. Furthermore, Bri2 has been discussed to act as chaperone for the amyloid precursor protein (APP) thereby reducing generation of the cytotoxic A $\beta$ peptides in HEK cells stably overexpressing APP [75]. These 
findings established Bri2 as modulator of amyloid neurodegenerative diseases. Notably, SPPL2b-dependent proteolysis liberates a small Bri2 ICD to the cytosol [69], that may translocate to the nucleus and act as transcriptional regulator [64]. Along this line, overexpression of Bri2 in HEK cells was found to downregulate mRNA levels of BACE1 ( $\beta$-site APP cleaving enzyme 1) in addition to inducing lysosomal degradation of the BACE1 protein [76]. Furthermore, Bri2 was shown to upregulate expression of the A $\beta$-degrading protease Insulin Degrading Enzyme (IDE) [77]. It will certainly be of interest to evaluate a potential role of the liberated Bri2 ICD as well as the membrane-bound NTF prior to its cleavage by SPPL2a/b in these contexts. Altogether, the physiological role of the proteolytic processing of Bri2 is not completely understood. Future studies will help to clarify if SPPL2b via cleavage of Bri2 or possibly also other substrates may play a modulating role in neurodegenerative processes. SPPL2a/b double-deficient mice do not show any major neuronal loss as it could be detected by routine histological examination (unpublished observation). However, it may be anticipated that absence of SPPL2a/b - though well compensated under basal conditions - may critically affect disease-relevant pathways in the brain, but also other organ systems, when mice are challenged in a certain way.

\subsection{SPPL2c:}

Evidence for SPPL2c protein expression under endogenous conditions is still pending. Based on the intronless gene architecture, SPPL2c was suggested to represent a redundant pseudogene. Overexpressed SPPL2c localises to the ER like SPP [47]. Therefore, a central question will be if substrate spectra and molecular functions of SPP and SPPL2c can be delineated from each other or whether SPPL2c merely represents a SPP backup system. To date, proteolytic activity of SPPL2c has not been demonstrated and similarly the physiological functions of SPPL2c remain unknown. In a tissue microarray analysis, SPPL2c expression 
was found in human brain, heart, skin, adrenal cortex, mammary gland and testis [19]. No knockout studies in mice have been reported yet. In a genome-wide association study [78], a single nucleotide polymorphism (SNP, rs17690703) close to the coding region of SPPL2c was found to be significantly associated with the susceptibility to idiopathic pulmonary fibrosis (IPF). IPF is a rare disease of unknown aetiology characterised by a fibrotic process in the lung interstitium which is associated with a high mortality if not treated by lung transplantation [79]. Lung fibrosis can also occur in the context of systemic diseases. Interestingly, the respective SNP was not significantly associated with the occurrence of interstitial lung disease in the context of systemic sclerosis [80]. Proof of SPPL2c protein expression in the lung is pending and it is therefore unclear how SPPL2c could be part of the IPF disease process, especially since a diverse range of cell types like alveolar epithelial cells, fibroblasts and immune cells is involved [79]. Thus, further work is needed to substantiate a pathophysiological relevance of the reported genetic association.

\subsection{SPPL3:}

The ability of SPPL3 to cleave substrate proteins without the requirement of a preceding ectodomain shedding has introduced unexpected mechanistic diversity into the SPP/SPPL protease family. Following the initial discovery of this property upon cleavage of the Foamy virus envelope protein [6], this was subsequently corroborated by the identification of cellular substrates $[30,31]$. SPPL3 is able to cleave a large set of Golgi-resident glycosyltransferases and glycan-modifying enzymes which are involved in protein $\mathrm{N}$ - and O-glycosylation as well as glycosaminoglycan biosynthesis. Major insights were provided by a mass spectrometric substrate identification approach utilising the 'secretome protein enrichment with click sugars (SPECS)' method [81]. All SPPL3 substrates which were identified in this screen and further experimentally validated are type II transmembrane proteins, as comprehensively listed in a 
recent review [23]. Mechanistically, SPPL3-mediated intramembrane cleavage induces the secretion of the substrate's ectodomain, thereby reducing the intracellular levels of active glycosyltransferases [30]. Consequently, SPPL3 overexpression leads to hypoglycosylation of cellular proteins in the secretory pathway and, vice versa, a depletion of SPPL3 to enhanced glycan-synthesis [30]. Based on these studies, SPPL3 has emerged as a major regulator of cellular protein glycosylation.

In light of such a critical function, it may not be too surprising that SPPL3 overexpression and knockdown are not well tolerated in cultured cell lines and associated with significant cytotoxicity [23]. As first in vivo model, a knockdown of SPPL3 in zebrafish leading to a neuronal cell death phenotype was reported [55]. In mice on a C57BL/6J background, constitutive ablation of SPPL3 led to lethality within the first days of life for which the reason is currently unknown [82]. This perinatal lethality was mirrored in mice homozygous for a D271A mutation within the catalytical GxGD motif indicating a critical role of the SPPL3 proteolytic activity [82]. In contrast, SPPL3-deficient mice on a mixed C57BL/6;129S5 background are viable and rather mildly affected with growth retardation, haematologic abnormalities and sterility in male homozygous mice [83]. Differential viability of knockout mice depending on the genetic background has been observed in several cases [84]. Based on its role as sheddase of glycosyltransferases and glycan-modifying enzymes, glycoproteins in tissues of $S P P L 3^{-/-}$mice are hyperglycosylated [30]. To what extent this is associated with the mentioned phenotypes and which target proteins are specifically involved remains to be analysed.

Among the major immune cell populations, SPPL3 expression is particularly prominent in natural killer (NK) cells [82]. By specifically ablating SPPL3 expression in the haematopoetic system or NK cells using a conditional SPPL3 knockout and Vav1-iCre and NKp46-iCre alleles, respectively, Hamblet et al. could demonstrate a cell-autonomous role of 
SPPL3 in NK cell maturation and function [82]. In these models, SPPL3 deficiency led to a significant reduction of peripheral NK cells in spleen and liver, which was caused by a reduced proliferation of $\mathrm{CD} 27^{+} \mathrm{CD} 11 \mathrm{~b}^{-}$precursors in the bone marrow and impaired survival of $\mathrm{CD} 27^{+} \mathrm{CD} 11 \mathrm{~b}^{+}$and $\mathrm{CD} 27^{-} \mathrm{CD} 11 \mathrm{~b}^{+} \mathrm{NK}$ cells in both bone marrow and periphery [82]. In addition, the remaining cells exhibited altered surface expression of several NK cell receptors and reduced cytotoxicity. These changes were not rescued in $S P P L 3^{-/ D 271 A}$ NK cells expressing the inactive SPPL3-D271A mutant which demonstrates a requirement of the SPPL3 proteolytic activity in this cell type. The substrate responsible for this specific phenotype of SPPL3-deficient or mutant mice is currently unknown. In line with studies in SPPL3-deficient murine embryonic fibroblasts (MEFs) [30], SPPL3 ${ }^{-/}$NK cells exhibited increased levels of the glycosyltransferase MGAT5. Interestingly, when analysing lectinbinding by these cells, no indication for a major hyper-glycosylation of cell-surface proteins was obtained. Therefore, it seems rather unlikely that disturbed protein glycosylation is the predominant underlying mechanism of the NK cell phenotype [82].

In cell-based experiments, a protease-independent function of SPPL3 in T cells has been unravelled [85]. SPPL3 knockdown in Jurkat $\mathrm{T}$ cells diminished the cytosolic $\mathrm{Ca}^{2+}$ entry and activation of the transcription factor NFAT upon activation of the T cell receptor (TCR). SPPL3 was found to facilitate the interaction of the ER protein STIM1 and the calcium channel Orail which is a key element of Store-operated calcium entry (SOCE) critically involved in $\mathrm{T}$ cell activation but also signal transduction in other immune and non-immune cells [86]. The differentiation of $\mathrm{T}$ cells was not negatively affected by SPPL3 deficiency which was demonstrated by normal numbers of $\mathrm{CD}^{+}$and $\mathrm{CD} 8^{+} \mathrm{T}$ cells in spleens of $\mathrm{Vavl}$ iCre SPPL3 knockout mice [82]. Therefore, these mice should represent a perfect system to evaluate the impact of SPPL3 on TCR signal transduction in primary murine T cells. Provided that the findings generated in Jurkat cells can be recapitulated in this system one may expect 
major impairments of $\mathrm{T}$ cell-dependent immune responses in these mice. The critical role of SOCE is not limited to T cells. Therefore, further studies based on the conditional SPPL3 allele in order to systematically analyse consequences of SPPL3 deficiency in different tissues seem to be mandatory with regard to its impact on $\mathrm{Ca}^{2+}$ signalling and protein glycosylation. It seems likely that additional yet unknown substrates and/or molecular functions of this protease will be revealed.

\section{Inhibitors of SPP/SPPL proteases}

Since the physiological function of SPP/SPPL proteases is more and more understood, their role in pathophysiological contexts, like cancer, malaria, virus infections and immune deficiencies, also becomes more evident [23]. Moreover, presenilins play a key role in the development of Alzheimer disease [87, 88]. Thus, development of efficient and specific inhibitors is one central aspect in GxGD protease research. So far, however, it has not been possible to identify inhibitors for all members of the SPP/SPPL family and compounds that specifically target only one member of the protease family are still missing.

Structures of selected known inhibitors of SPP/SPPL intramembrane proteases are depicted in Fig. 2 and their reported effects on the individual members of the SPP/SPPL family as well as $\gamma$-secretase are compiled in Table 2. Since proof of proteolytic activity for SPPL2c is pending, no information about its potential inhibitory profile is available. In general, a direct comparison of data from different studies regarding the effectivity of these compounds towards the individual SPP/SPPL proteases is challenging due to significant differences in the employed assay systems. SPP-mediated proteolysis has been reconstituted either using CHAPS-solubilised, in vitro translated SPP from microsomes or SPP expressed in E.coli which allowed testing of inhibitors in vitro $[89,90]$. In contrast, such assay formats 
have not been established yet for SPPL2a/b and SPPL3 so that the evaluation of inhibitors has to rely entirely on cell-based set-ups, either as a reporter assay [64] or simply by Western blot analysis of substrate cleavage [91]. In such systems, also the membrane-permeability as well as the affinity to cellular multi-drug export proteins will significantly influence the effectiveness of any compounds in addition to their immediate inhibitory potential. This may be particularly relevant regarding the effect on intracellularly located SPP/SPPL proteases and may explain why in cell-based assays much higher compound concentrations are required for effective inhibition of SPP as compared to in vitro set-ups [89]. Considering a therapeutic perspective, of course many additional compound characteristics like its toxicity, enteral absorption, tissue permeability and metabolism would need to be considered and optimised.

Prior to identification of SPP as the responsible protease, 1,3-di-(N-carboxybenzoyl-Lleucyl-L-leucyl) amino acetone ((Z-LL)2-ketone) was found to inhibit signal peptide processing [92]. Subsequently, a photocrosslinkable biotin-containing derivative of (Z-LL)2-ketone was used to isolate and identify SPP [3]. (Z-LL)2-ketone is a transition state analogue, which mimics leucine-rich hydrophobic amino acid sequences present in many substrates of SPP/SPPL proteases, and consequently inhibits substrate processing not only by SPP [89] but also by SPPL2a and SPPL2b [4, 5, 29, 47, 91]. This suggests that (Z-LL)2-ketone directly targets the active site of SPP/SPPL proteases, although the formal proof for this assumption is still missing. However, SPPL3 is not inhibited by this compound in a cellular context [6]. Importantly, (Z-LL)2-ketone has no effect on $\gamma$-secretase [89] which makes it unique among all currently known SPP/SPPL protease inhibitors (Table 2). Given that (Z-LL)2-ketone is an active site inhibitor these observations indicate spatial differences in the active site architecture already between different SPP/SPPL proteases, but most importantly between SPP/SPPLs and $\gamma$-secretase. Thus, (Z-LL)2-ketone may be regarded as a proof-of principle that the development of $\gamma$-secretase sparing SPP/SPPL inhibitors is possible 
which will have important implications for a therapeutic setting. Beyond this advantage, however, the applicability and effectiveness of (Z-LL)2-ketone in cell-based set-ups is limited since concentrations of up to $100 \mu \mathrm{M}$ are needed to achieve detectable inhibition [64].

Based on a similarity of the active centres, some activity-based probes developed to label $\gamma$-secretase also react with SPP [93, 94]. Similarly, several active site targeted $\gamma$ secretase inhibitors (GSIs), like L-685,458 [95, 96] or LY-411575 [97], also reduce SPP, SPPL2a and SPPL2b activity [29, 47, 89, 91, 98]. Again, these compounds fail to block SPPL3 [6], indicating that $\gamma$-secretase, SPP, SPPL2a and SPPL2b share a common structure in their catalytic centre, that is not conserved in SPPL3. Presumably, the binding position of these GSIs within the active site of GxGD proteases slightly differs from that of (Z-LL)2-ketone which does not target $\gamma$-secretase. Experiments with synthetic helical peptides that mimic the substrates of GxGD proteases led to the hypothesis that the site of initial substrate binding ("docking site") in GxGD proteases differs from that of proteolysis [99]. Photoaffinity-labelling experiments of SPP and presenilins suggested that $\gamma$-secretase substrate mimetics and transition state analogues bind to different sites in these proteases [99, 100]. Binding of these helical peptides to other members of the SPP/SPPL family has not been examined yet. N-[N-(3,5-difluorophenacetyl)-L-alanyl]-S-phenylglycine-t-butyl ester (DAPT), another peptide-based GSI, specifically targets the C-terminal fragment of presenilin at a position distinct from the catalytic site and thereby inhibits $\gamma$-secretase activity [101]. However, it does not block catalytic activity of SPP/SPPL family members [6, 69, 89, 91] pointing to a binding site that is only present in the $\gamma$-secretase complex but not in SPP/SPPL proteases. As demonstrated by the use of an $A \beta /$ Bri2 chimeric substrate, the GSIs Compound E and DBZ fail to inhibit SPPL2b, although the catalytic activity of SPP, SPPL2a and $\gamma$-secretase is blocked $[91,102,103]$, revealing subtle differences in the active site even within one subfamily of SPPL proteases. 
A recent chemical biological approach used active site-directed photophore walking probes based on the GSI L- 685,458 to analyse differences between the active sites of SPP and presenilins [104]. As expected, several non transition state GSIs blocked labelling of $\gamma$ secretase by the different activity-based probes. Surprisingly, these compounds, in particular avagacestat [105] and semagacestat [106], enhanced labeling of SPP [104]. At least, the SPPmediated cleavage of the Hepatitis virus core protein [51] does not seem to be influenced by these two GSIs. To what extent they can inhibit SPP activity in other assay systems has not been reported yet. However, these findings indicate that these inhibitors act in a different manner on the active site of these two GxGD proteases. Altogether, these findings in conjunction with the profiles of GxGD protease inhibitors currently available (Table 2) indicate that the active site architecture, though highly conserved in the primary structure, differs more than initially anticipated between the individual protease family members. However, so far, it is not obvious how existing compounds can be modified to specifically target only one individual SPP/SPPL family member and the particularities of the SPPL3 active site remain enigmatic. Since the knowledge on the SPP/SPPL cleavage sites within their substrates and on their individual preferences of substrate recognition are still very limited, optimisation of peptide-based active site inhibitors is additionally complicated. To finally identify the precise binding sites of the individual compounds to the enzymes and elucidate the exact mechanism of inhibition, co-crystallisation of the respective inhibitors and proteases is required. Due to the pronounced hydrophobicity and integration into the lipid environment of cellular membranes this is a technically demanding task that, so far, has not been successfully solved for any vertebrate SPPL/SPPL protease. The atomic structure of the human $\gamma$-secretase complex has recently been solved [107], however co-crystals with the different inhibitors are still pending. 


\section{Lessons from clinical studies with $\gamma$-secretase inhibitors}

Though therapeutically applicable SPP/SPPL inhibitors are not yet available, GSIs have been under intensive clinical investigation. Among the nearly 100 proteins cleaved by $\gamma$-secretase [21], processing of the Amyloid Precursor Protein (APP) and the Notch1 receptor may be regarded as the clinically most relevant substrates. The proteolytic activity of $\gamma$-secretase plays a pivotal role in Notch1-dependent signal transduction [57]. Notch1 as well as the closely related other Notch receptors are major regulators of cell fate decisions, cellular proliferation and differentiation [108]. Upon binding of their ligands like Jagged and Delta on neighbouring cells, Notch receptors are cleaved in their extracellular domain by ADAM proteases thereby generating a Notch C-terminal stub. This protein fragment then is further processed by $\gamma$-secretase to liberate the Notch intracellular domain (NICD) to the cytosol which subsequently translocates to the nucleus to alter gene transcription $[57,108]$. Importantly, Notch-dependent signalling is dysregulated in several types of cancers including various leukemias, making this pathway an attractive therapeutic target [109].

A primary rationale for the development of GSIs was the role of $\gamma$-secretase in APP processing where the intramembrane cleavage liberates the neurotoxic, aggregation-prone $\mathrm{A} \beta$ peptides that are a hallmark of Alzheimer disease [87, 110]. By blocking the generation of this amyloidogenic protein fragment, it was hoped that neurodegeneration could be prevented or at least significantly slowed down. Therefore, several highly effective GSIs have been developed and in some cases even pushed forward to clinical trials [111]. However, as a major limitation in these studies severe adverse effects were observed. In case of the Eli Lilly compound Semagecestat a randomised, double-blind and placebo-controlled phase III trial with more than 1500 Alzheimer disease patients was performed [112]. Many patients treated with semagacestat experienced gastrointestinal side-effects, hypopigmentation of hair and eyelashes and developed non-melanoma skin cancers presumably reflecting the GSI-induced 
impairment of Notch processing and signalling [112]. Furthermore, the compound did not have the anticipated effects on cerebrospinal fluid levels of the $A \beta$ fragments and, even worse, caused a more severe cognitive decline than observed in the placebo-treated control group leading to the early termination of this trial [112]. Obviously, the described side-effects may be considered especially problematic in a therapeutic setting where long-term treatment would be required as in the case of Alzheimer disease. A potential contribution of SPP/SPPL proteases to the toxicity of $\gamma$-secretase-inhibitors is currently underexplored since several of them including the clinical phase compound RO4929097 also inhibit SPP [51]. Beyond dementia, therapeutic $\gamma$-secretase inhibition, e.g, by MK-0752 and RO4929097, may have a potential benefit in oncology where blocking procarcinogenic Notch signalling would be the primary target. Here, the threshold of tolerable side-effects may also be higher due to a limited duration of therapy and the considerable adverse effects associated with alternative cytostatic treatments. Currently, several phase I and phase II clinical trials with patients suffering from malignant central nervous system tumours like glioma and astrocytoma as well as other cancers are conducted [113-115].

What these trials mean for the future of $\gamma$-secretase as a drug target in general and GSIs in the in the treatment of Alzheimer disease has been discussed elsewhere $[116,117]$. Here, we aim to highlight those insights that have implications for the ongoing development of SPP/SPPL family inhibitors. Based on the side-effects that can be associated with $\gamma$ secretase inhibition, it will be of pivotal importance to develop SPP/SPPL inhibitors that completely spare $\gamma$-secretase. Otherwise applicability of these compounds may experience similar limitations as semagacestat [112]. As described, so far all known SPP/SPPL family inhibitors except (Z-LL)2-ketone also target $\gamma$-secretase [89] (Table 2).

One major pitfall in the clinical trials of for example Semagecestat was presented by the lacking discrimination of the inhibitor for processing of different $\gamma$-secretase substrates 
since this compound blocks proteolysis of APP as well as Notch1 with a comparable efficiency [118]. Transferred to the development of SPP/SPPL inhibitors this clearly highlights the need for compounds that selectively target individual family members and - if possible - individual protease-substrate-pairs. This notion is further strengthened by the severe phenotypes of especially SPP- and SPPL3-deficient mice that show embryonic or perinatal lethality on a C57BL/6 background, respectively [51, 82]. To selectively block proteolysis of specific SPP/SPPL substrates, as it was attempted with the development of Notch-sparing GSIs [111], may seem challenging and rather speculative at the moment. In contrast, at least the design of protease-specific inhibitors appears more realistic which is supported by the significantly different effects of the currently known compounds on the individual SPP/SPPL proteases (Table 2). Even for the very closely related proteases SPPL2a and SPPL2b with a broadly overlapping substrate spectrum Ran et al. observed with their A $\beta /$ Bri2 model substrate that SPPL2a was inhibited about 12- and 100-fold more effectively by (Z-LL)2-ketone and LY-411575, respectively, than SPPL2b. In contrast, L685,458 exhibited a comparable efficacy against both proteases [91]. Further modification of already existing molecules as well as high throughput screening for novel lead compounds will be required to develop specific inhibitors of individual SPP/SPPL proteases.

\section{SPP/SPPL proteases as therapeutic targets}

In the following we will discuss and speculate about potential disease contexts where SPP/SPPL protease inhibitors may be beneficial. Starting with SPP itself, the knowledge on the pathophysiological functions is very limited as pointed out before. Nevertheless, two putative applications of SPP inhibitors have been proposed: certain viral infections and malaria. Whereas in the first case the host cell's SPP is involved in processing newly synthesised viral proteins, in malaria the parasite's SPP is critical for the well-being of the 
pathogen. This means that either the human or the plasmodium SPP would need to be targeted by inhibitors. Regarding a systemic inhibition of SPP in humans, potential toxicity and sideeffects of this approach will need to be carefully investigated since a constitutive knockout in mice leads to perinatal lethality. This may be less problematic in the context of malaria. Human and plasmodium SPP showed significant differences in their affinity to some GSIs [91]. Therefore, the design of a potent inhibitor of plasmodium SPP which only mildly acts on human SPP and the SPPLs may seem realistic and should prevent any adverse effects due cross-inhibition of host proteases. We will briefly summarise the available experimental evidence on the role of SPP in viral infections and in plasmodium parasites on which the ideas to exploit this therapeutically are based.

\section{$\underline{5.1 \text { The role of host cell SPP in viral infections }}$}

SPP is involved in the processing of several viral proteins, of which the Hepatitis C Virus (HCV) core protein was the first discovered and consequently represents the best studied example [119]. Core proteins from HCV-related viruses like the GB virus B (GBV-B) and the hepacivirus $(\mathrm{EHcV})$ are processed in a similar way $[42,120]$. HCV is a human-pathogenic RNA virus causing chronic hepatitis with a high risk of progression to liver cirrhosis and the development of hepatocellular carcinoma [121]. In an infected cell, the viral proteins are synthesised as a polyprotein composed of the amino terminal structural proteins core, E1 and E2 as well as non-structural proteins. An internal signal sequence between the core and the E1 protein directs the nascent protein to the ER and induces translocation of the E1 protein into the ER lumen. There, the E1 protein is cleaved off by signal peptidase, leaving the core anchored to the ER membrane via the remaining signal sequence (Fig. 3A) [122], which is further processed by SPP $[119,123]$. In line with the substrate requirements of SPP and most SPPL proteases, the preceding cleavage of the core protein by signal peptidase seems to be a 
prerequisite for further processing by SPP [124]. After cleavage by SPP, the mature core protein translocates from the ER to lipid droplets for virus assembly [119, 125]. Extensive mutagenesis studies have been performed and revealed several residues within the hydrophobic signal peptide region that are critical for SPP cleavage with some differences between HCV sub-strains [26, 39, 43, 119, 125-128]. Cleavage and maturation of HCV core protein could be blocked by (Z-LL)2-ketone [26, 124, 125, 127], L685,458 [128], LY-411575 [51, 98] and RO4929097 [51] in cell culture models. Furthermore, pharmacological inhibition, downregulation of SPP protein by siRNA or expression of processing-resistant core protein mutants led to reduced viral production [39, 43, 51, 98, 128, 129]. Based on experiments in cultured cells, modulation of SPP activity appears to be a promising approach to suppress virus propagation. Since rodents are not susceptible to HCV infection, experimental in vivo evidence for this concept cannot be easily obtained [130].

Beyond its role in virus production, the $\mathrm{HCV}$ core protein was shown to interact with a variety of host cell proteins and may directly be involved in inducing pathological changes associated with HCV infection [122]. Transgenic expression of this protein in mice induces liver steatosis, insulin resistance and hepatocellular carcinoma [51, 122]. Unexpectedly, Aizawa et al. observed that SPP inhibition did not induce a significant accumulation of the uncleaved immature core protein but rather led to its depletion because it was subjected to proteosomal degradation dependent on the ubiquitin ligase TRC8 [51]. Therefore, SPP inhibition significantly reduced the overall cellular core protein levels in cultured cells. This effect could be recapitulated in HCV core transgenic mice upon administration of LY-411575. This treatment also significantly improved lipid accumulation and insulin resistance associated with transgene expression [51]. Importantly, a similar improvement of these core protein-induced phenotypes was observed with a heterozygous SPP knockout allele $\left(S P P^{+/-}\right)$ bred into this transgenic line. Though a constitutive SPP knockout in mice is lethal, 
heterozygous animals are not detectably compromised [51]. This indicates that SPP inhibition upon $\mathrm{HCV}$ infection may not only be beneficial by blocking virus propagation, but also by preventing pathogenetic effects of the $\mathrm{HCV}$ protein itself by inducing its proteasomal degradation. Based on the positive effects in $S P P^{+/}$mice, it seems possible that for the latter mechanism already a partial inhibition of SPP could be sufficient which would of course significantly reduce the risk of any toxic side effects. Still, no prophylactic vaccine in order to prevent HCV infection is available [121]. Though antiviral therapeutics can cure many patients, treatment fails in some cases where an additional therapeutic defence line based on SPP could be of use.

In addition to $\mathrm{HCV}$, also the core protein of the classical swine fever virus [131] and the glycoprotein precursor of the Bunyamwera orthobunyavirus [132] were found to be processed by SPP. In the latter case, knockdown of SPP impaired spreading of viruses from infected to neighbouring cells [132]. This argues for a functional relevance of the identified proteolytic cleavage in the infection cycle [132]. Since some members of the Bunyavirus family are serious human pathogens, this finding will deserve further investigations.

Moreover, SPP has been implicated in infections with Herpes simplex-1 (HSV-1) and Human Cytomegaly (CMV) viruses, both belonging to the family of Herpesviridae. The virus replication of HSV-1 in infected rabbit skin cells was reduced upon shRNA treatment against SPP, overexpression of dominant negative SPP as well as pharmacological inhibition of the protease $[133,134]$. A suppression of HSV-1 replication was also seen upon administration of (Z-LL)2-ketone to the eyes of ocularly infected mice [134]. Mechanistically, SPP was shown to interact with the viral glycoprotein $\mathrm{K}$ as identified in a yeast two-hybrid screen [133]. How precisely the proteolytic activity of SPP is involved in this context has not been examined yet. This also applies to a role of SPP upon CMV infection. There, SPP was found to be part of a central immune evasion mechanism of the virus, which involves a downregulation of MHCI 
complexes induced by the viral protein US2 [135]. Altogether, these various examples indicate that the function of SPP in viral infection should be further explored and that SPP inhibitors may of potential benefit in this area.

\subsection{The role of SPP in Plasmodium parasites}

Malaria is a zoonosis caused by protozoan Plasmodium spp parasites transmitted by Anopheles mosquitoes [136]. In humans, the parasite initially infects hepatocytes, but subsequently replicates in erythrocytes [136]. All Plasmodium species share one SPP homologue (PISPP) with approximately 30\% identity to human SPP [137]. Similar to mammalian SPP, also PISPP localises to the endoplasmic reticulum [138, 139]. Several groups could show susceptibility of PISPP to (Z-LL)2-ketone [91, 137, 138] as well as GSIs like L-685,458 [91, 138] or LY-411575 [91, 137, 140]. It should be mentioned that proof of proteolytic activity so far largely relies on processing of artificial model substrates (Fig. 3B). The only reported plasmodium-intrinsic substrate is the signal peptide of the HSP101 protein, a component of the protein export machinery [138]. However, also in this case evidence is limited to overexpression systems. Thus, altogether physiological substrates of P1SPP remain largely elusive to date.

Li et al. report that in multiple attempts to disrupt the PISPP gene no viable parasites were obtained from which they conclude an essential role of this protease in Plasmodium falciparum [141]. In agreement with this, pharmacological inhibition of SPP resulted in impaired parasite growth [139-142]. Mechanistically, it was shown that SPP inhibition sensitises the parasites to ER stress [140]. This points to a role of PISPP in the ERAD process (Fig. 3B) which agrees well with recently obtained similar findings on mammalian and yeast 
SPP $[50,52]$. In general, a reduced number of ERAD proteins in Plasmodium as compared to mammalian cells could account for its high sensitivity to ER stress [140].

Still under debate is the developmental stage of Plasmodium being affected by PISPP inhibition. Parvanova et al. showed impaired plasmodium replication within hepatocytes in cultured as well as in vivo models upon treatment with LY411,575 [142]. Parasite invasion into these cells was not affected and rather minor effects were observed on blood stages of the parasite [142]. Harbut et al. confirmed these findings using the mouse-infecting malaria species $P$. yoelii and the hepatocyte cell line HepG2 and found parasite load to be reduced by NITD731, NITD679 and LY411,575 [140]. In contrast, Li et al. found specifically erythrocyte invasion and growth within these cells affected by SPP inhibition [141]. The effects on intraerythrocyte parasite growth were confirmed by Marapana et al. [139], however, the invasion of $P$. falciparum into red blood cells was not impaired in this study [139].

In light of potential side-effects it seems encouraging that the determined $\mathrm{IC}_{50}$ values of different SPP inhibitors on Plasmodium yoelli replication in HepG2 cells were in the low nanomolar range whereas impairment of host cell growth was only seen beyond a concentration of $10 \mu \mathrm{M}$ [140]. Possibly, this can be further improved by designing inhibitors with a higher affinity to PISPP than to mammalian SPP and SPPL proteases. If this can be achieved, PISPP appears to be an attractive new concept for the treatment of malaria.

With estimated several millions of Plasmodium infections each year, malaria is still a major reason of morbidity and mortality in many parts of Africa, Asia and Latin America [143]. Resistance of the parasites against commonly used therapeutics as well as of the vector, Anopheles mosquitoes, against many insecticides makes this disease an ongoing medical problem [143]. In this context, new potential drug targets like PISPP may help to improve the situation 


\subsection{Could SPPL2a inhibitors serve as immunosuppressants?}

Based on the distinct immunological phenotype of SPPL2a-deficient mice in the absence of any major disabilities, we and others have proposed that pharmacological SPPL2a inhibition may be useful to deplete B cells and dendritic cells in order to treat autoimmunity $[29,58$, 59]. Our current preliminary understanding of the mechanisms involved in this phenotype, which is induced by the accumulation of the uncleaved CD74 NTF [29], are summarised in Fig. 4. In SPPL2a-deficient B cells, CD74 NTF disturbs endocytic membrane trafficking leading to the accumulation of characteristic endosome-derived vacuoles [29]. Presumably, this trafficking alteration is directly or indirectly responsible for the reduced surface presence of two receptors with a central role in B cell maturation: BAFF-R, the receptor for the cytokine BAFF (B cell-activating factor) and the B cell antigen receptor (BCR). In case of the $\mathrm{BCR}$, a redistribution of the receptor to intracellular compartments has been observed [144]. Since signals from both the BAFF-R as well as the BCR are required for the survival of transitional stage B cells in order to progress to functional maturity, depletion of these two receptors likely plays a critical role for the B cell maturation defect.

With regard to the BCR, the downstream signalling responses of this receptor, in particular the PI3K/Akt/FOXO axis, are disturbed in SPPL2a $a^{-/}$B cells [144]. In addition to the CD74 NTF-induced mis-sorting of the receptor, also direct inhibitory effects of this accumulating fragment on kinases, which are part of this pathway, seem conceivable [144]. Interestingly, enhanced signalling of the BAFF-R and the BCR have been implicated in the development of autoimmunity [145], which may be counteracted by an inhibition of SPPL2a. Deeper insights are required regarding the precise molecular interaction partners of the CD74 NTF that are responsible for inducing these striking cellular changes. Furthermore, nothing is known about the mechanisms leading to the loss of DCs in SPPL2a-deficient mice. Since the 
BAFF-R and the BCR are B cell specific receptors, the described findings cannot be immediately transferred to DCs.

Beyond a better understanding of the precise mechanism, several prerequisites would need to be fulfilled to pursue SPPL2a inhibition as a therapeutic approach. First of all, potent, SPPL2a-specific inhibitors sparing $\gamma$-secretase and also other SPP/SPPL proteases, which are not involved in CD74 proteolysis [60], would be needed. Currently, it remains elusive if the pathways triggered by the CD74 NTF in murine cells work equivalently in humans and lead to a depletion of B cells and/or DCs like in mice. In addition to the initiation of immune responses, DCs also play a central for the maintenance of immunological tolerance. Therefore, in some cases a global DC depletion in mice has resulted in autoimmune pathology [146]. This is apparently not the case in SPPL2a-deficient mice. Nevertheless, a more detailed analysis of the impact of SPPL2a deficiency/ inhibition on different DC subsets and the functionality of the remaining DCs with regard to cytokine secretion and in particular migration, which is influenced by CD74, is strongly advocated [147]. The SPPL $2 a^{-/-}$mouse models analysed to date exhibit a constitutive ablation of this gene. An important question will be if a therapeutic SPPL2a inhibition - even if it could impair the production of new B cells - would also be capable to significantly lower titers of pre-formed auto-antibodies. To a large extent, antibody-secreting plasma cells lose the expression of their antigenpresentation machinery including CD74 [148]. Therefore, it is unclear if these cells could be effectively targeted by SPPL2a inhibitors. At least some insights into this aspect, could be obtained by analysing inducible SPPL2a knockout mice. However, the positive effects of B cell depletion in autoimmunity do not seem to be limited to the reduction of autoantibodies as revealed by mouse models with B cells incapable of immunoglobulin secretion [149]. Furthermore, also in patients positive clinical responses to B cell depletion were observed despite persisting autoantibodies $[145,150,151]$. In general B cell depletion has proven to be 
beneficial in a number of autoimmune diseases including systemic lupus erythematosus [152], rheumatoid arthritis [153], anti-neutrophil cytoplasmic autoantibody-associated vasculitis [154], primary membranous nephropathy [155], pemphigus vulgaris [156] and multiple sclerosis [157]. In all these trials, targeting of B cells was achieved with the therapeutic antibody rituximab directed against the B cell antigen CD20. Obviously, it would have a variety of practical advantages, including the possibility of oral administration, if a similar outcome could be achieved with a small molecule SPPL2a inhibitor. Possibly, the presumed concurrent depletion of DCs may even lead to increased efficacies over established therapeutics. Therefore, provided that the above discussed prerequisites can be successfully met, SPPL2a inhibition may represent a promising approach for therapeutic immunosuppression.

\subsection{Possible perspectives for SPPL2b, SPPL2c and SPPL3?}

In contrast to the therapeutic potential of SPP and SPPL2a, much less is known about the physiological functions of the remaining SPP/SPPL-family members. Therefore, a possible clinical benefit from inhibiting these proteases is currently speculative. With regard to SPPL2b, its role in the central nervous system will certainly deserve further investigation and may reveal possible applications. If involvement in any pathophysiologically relevant pathway can be unravelled, SPPL2b may become a near-ideal target. Since SPPL2b-deficient mice show no major overt phenotype, the risk of adverse effects may be rather low. In the case of SPPL2c, the link to IPF is of potential medical interest. However, this is so far only based on genetic association data. If an impact of SPPL2c on the pathophysiology of this disease can be consolidated, therapeutic modulation of SPPL2c activity may become of interest at some point. In light of the major impact of SPPL3 on cellular protein glycosylation pathways, a systemic inhibition of this protease may be risky. Nevertheless, based on the NK 
cell phenotype of SPPL3-deficient mice therapeutic targeting of this cell type in disorders with NK cell autoreactivity [158] could be envisaged.

\section{$\underline{\text { 6. Conclusions }}$}

Despite major progress over the last years, our understanding of the pathophysiological functions of SPP/SPPL proteases is far from complete. Further work is required especially in those cases where constitutive knockouts in mice are lethal. The generation and analysis of tissue and cell type-specific knockout mice will hopefully fill this gap. In particular for SPP, this will be crucial in order to decipher potential side effects of therapeutic SPP inhibitors. Nevertheless, based on already available data promising perspectives for the two family members SPP and SPPL2a as therapeutic targets have been revealed which deserve further attention. However, to pursue this, major efforts for the identification and/or design of novel potent and specific inhibitors is an essential prerequisite. It can be expected that this will go along with exciting insights regarding the active centre geometry and cleavage mechanism of individual SPP/SPPL proteases as well as $\gamma$-secretase. 
$\underline{\text { Acknowledgments }}$

This work was supported by the Deutsche Forschungsgemeinschaft as part of the SFB877 (project B7, to B.S.), the research group FOR2290 (project FL 635/ 3-1 to R.F.), the Cluster of Excellence "Inflammation at Interfaces" as well as grants SCHR 1284/1-1 and FL 635/2-1. 


\section{REFERENCES}

[1] C.P. Ponting, M. Hutton, A. Nyborg, M. Baker, K. Jansen, T.E. Golde, Identification of a novel family of presenilin homologues, Hum Mol Genet 11 (2002) 1037-1044.

[2] A.P. Grigorenko, Y.K. Moliaka, G.I. Korovaitseva, E.I. Rogaev, Novel class of polytopic proteins with domains associated with putative protease activity, Biochemistry (Mosc. ) 67 (2002) 826-835.

[3] A. Weihofen, K. Binns, M.K. Lemberg, K. Ashman, B. Martoglio, Identification of signal peptide peptidase, a presenilin-type aspartic protease, Science 296 (2002) 2215-2218.

[4] R. Fluhrer, G. Grammer, L. Israel, M.M. Condron, C. Haffner, E. Friedmann, C. Bohland, A. Imhof, B. Martoglio, D.B. Teplow, C. Haass, A gamma-secretase-like intramembrane cleavage of TNFalpha by the GxGD aspartyl protease SPPL2b, Nat Cell Biol 8 (2006) 894896.

[5] V. Kirkin, N. Cahuzac, F. Guardiola-Serrano, S. Huault, K. Luckerath, E. Friedmann, N. Novac, W.S. Wels, B. Martoglio, A.O. Hueber, M. Zornig, The Fas ligand intracellular domain is released by ADAM10 and SPPL2a cleavage in T-cells, Cell Death Differ 14 (2007) 1678-1687.

[6] M. Voss, A. Fukumori, P.H. Kuhn, U. Kunzel, B. Klier, G. Grammer, M. Haug-Kroper, E. Kremmer, S.F. Lichtenthaler, H. Steiner, B. Schröder, C. Haass, R. Fluhrer, Foamy virus envelope protein is a substrate for signal peptide peptidase-like 3 (SPPL3), J Biol Chem 287 (2012) 43401-43409.

[7] M.S. Wolfe, W. Xia, B.L. Ostaszewski, T.S. Diehl, W.T. Kimberly, D.J. Selkoe, Two transmembrane aspartates in presenilin-1 required for presenilin endoproteolysis and gammasecretase activity, Nature 398 (1999) 513-517.

[8] H. Steiner, C. Haass, Intramembrane proteolysis by presenilins, Nat. Rev. Mol. Cell Biol 1 (2000) 217-224.

[9] H. Steiner, M. Kostka, H. Romig, G. Basset, B. Pesold, J. Hardy, A. Capell, L. Meyn, M.L. Grim, R. Baumeister, K. Fechteler, C. Haass, Glycine 384 is required for presenilin-1 function and is conserved in bacterial polytopic aspartyl proteases, Nat. Cell Biol 2 (2000) 848-851.

[10] C.F. LaPointe, R.K. Taylor, The type 4 prepilin peptidases comprise a novel family of aspartic acid proteases, J Biol Chem 275 (2000) 1502-1510.

[11] S.L. Bardy, K.F. Jarrell, Cleavage of preflagellins by an aspartic acid signal peptidase is essential for flagellation in the archaeon Methanococcus voltae, Mol Microbiol 50 (2003) 1339-1347.

[12] M. Voss, B. Schröder, R. Fluhrer, Mechanism, specificity, and physiology of signal peptide peptidase (SPP) and SPP-like proteases, Biochim. Biophys. Acta 1828 (2013) 28282839. 
[13] M. Lettau, M. Voss, H. Ebsen, D. Kabelitz, O. Janssen, Differential protein-protein interactions of full length human FasL and FasL fragments generated by proteolysis, Exp Cell Res 320 (2014) 290-301.

[14] L. Martin, R. Fluhrer, C. Haass, Substrate requirements for SPPL2b-dependent regulated intramembrane proteolysis, J Biol Chem 284 (2009) 5662-5670.

[15] B. Schrul, K. Kapp, I. Sinning, B. Dobberstein, Signal peptide peptidase (SPP) assembles with substrates and misfolded membrane proteins into distinct oligomeric complexes, Biochem J 427 (2010) 523-534.

[16] S. Hüttl, F. Helfrich, T. Mentrup, S. Held, A. Fukumori, H. Steiner, P. Saftig, R. Fluhrer, B. Schröder, Substrate determinants of signal peptide peptidase-like 2a (SPPL2a)-mediated intramembrane proteolysis of the invariant chain CD74, Biochem J 473 (2016) 1405-1422.

[17] D. Edbauer, E. Winkler, J.T. Regula, B. Pesold, H. Steiner, C. Haass, Reconstitution of gamma-secretase activity, Nat. Cell Biol 5 (2003) 486-488.

[18] A. Fukumori, R. Fluhrer, H. Steiner, C. Haass, Three-amino acid spacing of presenilin endoproteolysis suggests a general stepwise cleavage of gamma-secretase-mediated intramembrane proteolysis, J. Neurosci 30 (2010) 7853-7862.

[19] E. Friedmann, M.K. Lemberg, A. Weihofen, K.K. Dev, U. Dengler, G. Rovelli, B. Martoglio, Consensus analysis of signal peptide peptidase and homologous human aspartic proteases reveals opposite topology of catalytic domains compared with presenilins, J Biol Chem 279 (2004) 50790-50798.

[20] R. Kopan, M.X. Ilagan, Gamma-secretase: proteasome of the membrane?, Nat. Rev. Mol. Cell Biol 5 (2004) 499-504.

[21] A. Haapasalo, D.M. Kovacs, The many substrates of presenilin/gamma-secretase, J Alzheimers Dis 25 (2011) 3-28.

[22] A.C. Nyborg, K. Jansen, T.B. Ladd, A. Fauq, T.E. Golde, A signal peptide peptidase (SPP) reporter activity assay based on the cleavage of type II membrane protein substrates provides further evidence for an inverted orientation of the SPP active site relative to presenilin, J Biol Chem 279 (2004) 43148-43156.

[23] T. Mentrup, R. Fluhrer, B. Schroder, Latest emerging functions of SPP/SPPL intramembrane proteases, Eur J Cell Biol (2017).

[24] S.F. Lichtenthaler, C. Haass, H. Steiner, Regulated intramembrane proteolysis--lessons from amyloid precursor protein processing, J Neurochem 117 (2011) 779-796.

[25] G. Struhl, A. Adachi, Requirements for presenilin-dependent cleavage of notch and other transmembrane proteins, Mol. Cell 6 (2000) 625-636.

[26] M.K. Lemberg, B. Martoglio, Requirements for signal peptide peptidase-catalyzed intramembrane proteolysis, Mol. Cell 10 (2002) 735-744.

[27] S.A. Laurent, F.S. Hoffmann, P.H. Kuhn, Q. Cheng, Y. Chu, M. Schmidt-Supprian, S.M. Hauck, E. Schuh, M. Krumbholz, H. Rubsamen, J. Wanngren, M. Khademi, T. Olsson, T. Alexander, F. Hiepe, H.W. Pfister, F. Weber, D. Jenne, H. Wekerle, R. Hohlfeld, S.F. 
Lichtenthaler, E. Meinl, gamma-Secretase directly sheds the survival receptor BCMA from plasma cells, Nat Commun 6 (2015) 7333.

[28] J.M. Boname, S. Bloor, M.P. Wandel, J.A. Nathan, R. Antrobus, K.S. Dingwell, T.L. Thurston, D.L. Smith, J.C. Smith, F. Randow, P.J. Lehner, Cleavage by signal peptide peptidase is required for the degradation of selected tail-anchored proteins, J Cell Biol 205 (2014) 847-862.

[29] J. Schneppenheim, R. Dressel, S. Hüttl, R. Lüllmann-Rauch, M. Engelke, K. Dittmann, J. Wienands, E.L. Eskelinen, I. Hermans-Borgmeyer, R. Fluhrer, P. Saftig, B. Schröder, The intramembrane protease SPPL2a promotes B cell development and controls endosomal traffic by cleavage of the invariant chain, J Exp Med 210 (2013) 41-58.

[30] M. Voss, U. Kunzel, F. Higel, P.H. Kuhn, A. Colombo, A. Fukumori, M. Haug-Kroper, B. Klier, G. Grammer, A. Seidl, B. Schröder, R. Obst, H. Steiner, S.F. Lichtenthaler, C. Haass, R. Fluhrer, Shedding of glycan-modifying enzymes by signal peptide peptidase-like 3 (SPPL3) regulates cellular N-glycosylation, EMBO J 33 (2014) 2890-2905.

[31] P.H. Kuhn, M. Voss, M. Haug-Kroper, B. Schroder, U. Schepers, S. Brase, C. Haass, S.F. Lichtenthaler, R. Fluhrer, Secretome analysis identifies novel signal Peptide peptidaselike 3 (Spp13) substrates and reveals a role of Sppl3 in multiple Golgi glycosylation pathways, Mol Cell Proteomics 14 (2015) 1584-1598.

[32] M. Freeman, Rhomboid proteases and their biological functions, Annu Rev Genet 42 (2008) 191-210.

[33] R. Fluhrer, A. Fukumori, L. Martin, G. Grammer, M. Haug-Kroper, B. Klier, E. Winkler, E. Kremmer, M.M. Condron, D.B. Teplow, H. Steiner, C. Haass, Intramembrane proteolysis of GXGD-type aspartyl proteases is slowed by a familial Alzheimer disease-like mutation, $\mathrm{J}$ Biol Chem 283 (2008) 30121-30128.

[34] Y. Qi-Takahara, M. Morishima-Kawashima, Y. Tanimura, G. Dolios, N. Hirotani, Y. Horikoshi, F. Kametani, M. Maeda, T.C. Saido, R. Wang, Y. Ihara, Longer forms of amyloid beta protein: implications for the mechanism of intramembrane cleavage by gamma-secretase, J Neurosci 25 (2005) 436-445.

[35] H. Steiner, R. Fluhrer, C. Haass, Intramembrane proteolysis by gamma-secretase, J. Biol. Chem 283 (2008) 29627-29631.

[36] T. Sato, A.C. Nyborg, N. Iwata, T.S. Diehl, T.C. Saido, T.E. Golde, M.S. Wolfe, Signal peptide peptidase: biochemical properties and modulation by nonsteroidal antiinflammatory drugs, Biochemistry 45 (2006) 8649-8656.

[37] E. Winkler, F. Kamp, J. Scheuring, A. Ebke, A. Fukumori, H. Steiner, Generation of Alzheimer disease-associated amyloid beta42/43 peptide by gamma-secretase can be inhibited directly by modulation of membrane thickness, J Biol Chem 287 (2012) 21326-21334.

[38] R. Fluhrer, L. Martin, B. Klier, M. Haug-Kroper, G. Grammer, B. Nuscher, C. Haass, The alpha-helical content of the transmembrane domain of the British dementia protein-2 (Bri2) determines its processing by signal peptide peptidase-like 2b (SPPL2b), J Biol Chem 287 (2012) 5156-5163. 
[39] V. Oehler, A. Filipe, R. Montserret, C.D. da, G. Brown, F. Penin, J. McLauchlan, Structural analysis of hepatitis $\mathrm{C}$ virus core-E1 signal peptide and requirements for cleavage of the genotype 3a signal sequence by signal peptide peptidase, J. Virol 86 (2012) 7818-7828.

[40] M.L. Hemming, J.E. Elias, S.P. Gygi, D.J. Selkoe, Proteomic profiling of gammasecretase substrates and mapping of substrate requirements, PLoS. Biol 6 (2008) e257.

[41] Z. Ren, D. Schenk, G.S. Basi, I.P. Shapiro, Amyloid beta-protein precursor juxtamembrane domain regulates specificity of gamma-secretase-dependent cleavages, J Biol Chem 282 (2007) 35350-35360.

[42] P. Targett-Adams, T. Schaller, G. Hope, R.E. Lanford, S.M. Lemon, A. Martin, J. McLauchlan, Signal peptide peptidase cleavage of GB virus B core protein is required for productive infection in vivo, J. Biol. Chem 281 (2006) 29221-29227.

[43] P. Targett-Adams, G. Hope, S. Boulant, J. McLauchlan, Maturation of hepatitis C virus core protein by signal peptide peptidase is required for virus production, J. Biol. Chem 283 (2008) 16850-16859.

[44] M. Poggi, I. Kara, J.M. Brunel, J.F. Landrier, R. Govers, B. Bonardo, R. Fluhrer, C. Haass, M.C. Alessi, F. Peiretti, Palmitoylation of TNF alpha is involved in the regulation of TNF receptor 1 signalling, Biochim. Biophys. Acta 1833 (2013) 602-612.

[45] C. Kaether, C. Haass, H. Steiner, Assembly, trafficking and function of gammasecretase, Neurodegener. Dis 3 (2006) 275-283.

[46] R. Sannerud, C. Esselens, P. Ejsmont, R. Mattera, L. Rochin, A.K. Tharkeshwar, G. De Baets, V. De Wever, R. Habets, V. Baert, W. Vermeire, C. Michiels, A.J. Groot, R. Wouters, K. Dillen, K. Vints, P. Baatsen, S. Munck, R. Derua, E. Waelkens, G.S. Basi, M. Mercken, M. Vooijs, M. Bollen, J. Schymkowitz, F. Rousseau, J.S. Bonifacino, G. Van Niel, B. De Strooper, W. Annaert, Restricted Location of PSEN2/gamma-Secretase Determines Substrate Specificity and Generates an Intracellular Abeta Pool, Cell 166 (2016) 193-208.

[47] E. Friedmann, E. Hauben, K. Maylandt, S. Schleeger, S. Vreugde, S.F. Lichtenthaler, P.H. Kuhn, D. Stauffer, G. Rovelli, B. Martoglio, SPPL2a and SPPL2b promote intramembrane proteolysis of TNFalpha in activated dendritic cells to trigger IL-12 production, Nat Cell Biol 8 (2006) 843-848.

[48] J. Behnke, J. Schneppenheim, F. Koch-Nolte, F. Haag, P. Saftig, B. Schroder, Signalpeptide-peptidase-like 2a (SPPL2a) is targeted to lysosomes/late endosomes by a tyrosine motif in its C-terminal tail, FEBS Lett 585 (2011) 2951-2957.

[49] F.F. Hsu, C.T. Yeh, Y.J. Sun, M.T. Chiang, W.M. Lan, F.A. Li, W.H. Lee, L.Y. Chau, Signal peptide peptidase-mediated nuclear localization of heme oxygenase-1 promotes cancer cell proliferation and invasion independent of its enzymatic activity, Oncogene 34 (2015) 2360-2370.

[50] C.Y. Chen, N.S. Malchus, B. Hehn, W. Stelzer, D. Avci, D. Langosch, M.K. Lemberg, Signal peptide peptidase functions in ERAD to cleave the unfolded protein response regulator XBP1u, EMBO J 33 (2014) 2492-2506. 
[51] S. Aizawa, T. Okamoto, Y. Sugiyama, T. Kouwaki, A. Ito, T. Suzuki, C. Ono, T. Fukuhara, M. Yamamoto, M. Okochi, N. Hiraga, M. Imamura, K. Chayama, R. Suzuki, I. Shoji, K. Moriishi, K. Moriya, K. Koike, Y. Matsuura, TRC8-dependent degradation of hepatitis $\mathrm{C}$ virus immature core protein regulates viral propagation and pathogenesis, Nat Commun 7 (2016) 11379.

[52] D. Avci, S. Fuchs, B. Schrul, A. Fukumori, M. Breker, I. Frumkin, C.Y. Chen, M.L. Biniossek, E. Kremmer, O. Schilling, H. Steiner, M. Schuldiner, M.K. Lemberg, The yeast ER-intramembrane protease Ypf1 refines nutrient sensing by regulating transporter abundance, Mol. Cell 56 (2014) 630-640.

[53] A.P. Grigorenko, Y.K. Moliaka, M.C. Soto, C.C. Mello, E.I. Rogaev, The Caenorhabditis elegans IMPAS gene, imp-2, is essential for development and is functionally distinct from related presenilins, Proc Natl Acad Sci U S A 101 (2004) 14955-14960.

[54] D.J. Casso, S. Tanda, B. Biehs, B. Martoglio, T.B. Kornberg, Drosophila signal peptide peptidase is an essential protease for larval development, Genetics 170 (2005) 139-148.

[55] P. Krawitz, C. Haffner, R. Fluhrer, H. Steiner, B. Schmid, C. Haass, Differential localization and identification of a critical aspartate suggest non-redundant proteolytic functions of the presenilin homologues SPPL2b and SPPL3, J Biol Chem 280 (2005) 3951539523.

[56] A. Herreman, D. Hartmann, W. Annaert, P. Saftig, K. Craessaerts, L. Serneels, L. Umans, V. Schrijvers, F. Checler, H. Vanderstichele, V. Baekelandt, R. Dressel, P. Cupers, D. Huylebroeck, A. Zwijsen, F. Van Leuven, B. De Strooper, Presenilin 2 deficiency causes a mild pulmonary phenotype and no changes in amyloid precursor protein processing but enhances the embryonic lethal phenotype of presenilin 1 deficiency, Proc. Natl. Acad. Sci. U. S. A 96 (1999) 11872-11877.

[57] B. De Strooper, W. Annaert, P. Cupers, P. Saftig, K. Craessaerts, J.S. Mumm, E.H. Schroeter, V. Schrijvers, M.S. Wolfe, W.J. Ray, A. Goate, R. Kopan, A presenilin-1dependent gamma-secretase-like protease mediates release of Notch intracellular domain, Nature 398 (1999) 518-522.

[58] D.R. Beisner, P. Langerak, A.E. Parker, C. Dahlberg, F.J. Otero, S.E. Sutton, L. Poirot, W. Barnes, M.A. Young, S. Niessen, T. Wiltshire, U. Bodendorf, B. Martoglio, B. Cravatt, M.P. Cooke, The intramembrane protease Sppl2a is required for B cell and DC development and survival via cleavage of the invariant chain, J. Exp. Med 210 (2013) 23-30.

[59] H. Bergmann, M. Yabas, A. Short, L. Miosge, N. Barthel, C.E. Teh, C.M. Roots, K.R. Bull, Y. Jeelall, K. Horikawa, B. Whittle, B. Balakishnan, G. Sjollema, E.M. Bertram, F. Mackay, A.J. Rimmer, R.J. Cornall, M.A. Field, T.D. Andrews, C.C. Goodnow, A. Enders, B cell survival, surface BCR and BAFFR expression, CD74 metabolism, and CD8- dendritic cells require the intramembrane endopeptidase SPPL2A, J Exp Med 210 (2013) 31-40.

[60] J. Schneppenheim, S. Hüttl, T. Mentrup, R. Lüllmann-Rauch, M. Rothaug, M. Engelke, K. Dittmann, R. Dressel, M. Araki, K. Araki, J. Wienands, R. Fluhrer, P. Saftig, B. Schröder, The intramembrane proteases signal Peptide peptidase-like $2 \mathrm{a}$ and $2 \mathrm{~b}$ have distinct functions in vivo, Mol Cell Biol 34 (2014) 1398-1411. 
[61] B. Schröder, The multifaceted roles of the invariant chain CD74 - More than just a chaperone., Biochim. Biophys. Acta 1863 (2016) 1269-1281.

[62] D. Matza, A. Kerem, H. Medvedovsky, F. Lantner, I. Shachar, Invariant chain-induced B cell differentiation requires intramembrane proteolytic release of the cytosolic domain, Immunity 17 (2002) 549-560.

[63] S. Becker-Herman, G. Arie, H. Medvedovsky, A. Kerem, I. Shachar, CD74 is a member of the regulated intramembrane proteolysis-processed protein family, Mol Biol Cell 16 (2005) 5061-5069.

[64] T. Mentrup, R. Hasler, R. Fluhrer, P. Saftig, B. Schröder, A Cell-Based Assay Reveals Nuclear Translocation of Intracellular Domains Released by SPPL Proteases, Traffic 16 (2015) 871-892.

[65] N. Gil-Yarom, L. Radomir, L. Sever, M.P. Kramer, H. Lewinsky, C. Bornstein, R. Blecher-Gonen, Z. Barnett-Itzhaki, V. Mirkin, G. Friedlander, L. Shvidel, Y. Herishanu, E.J. Lolis, S. Becker-Herman, I. Amit, I. Shachar, CD74 is a novel transcription regulator, Proc Natl Acad Sci U S A 114 (2017) 562-567.

[66] D. Matza, A. Kerem, I. Shachar, Invariant chain, a chain of command, Trends Immunol 24 (2003) 264-268.

[67] J. Schneppenheim, S. Hüttl, A. Kruchen, R. Fluhrer, I. Muller, P. Saftig, R. Schneppenheim, C.L. Martin, B. Schröder, Signal-peptide-peptidase-like 2a is required for CD74 intramembrane proteolysis in human B cells, Biochem Biophys Res Commun 451 (2014) 48-53.

[68] A.L. Bronckers, N. Guneli, R. Lullmann-Rauch, J. Schneppenheim, A.P. Moraru, N. Himmerkus, T.J. Bervoets, R. Fluhrer, V. Everts, P. Saftig, B. Schroder, The intramembrane protease SPPL2A is critical for tooth enamel formation, J Bone Miner Res (2013).

[69] L. Martin, R. Fluhrer, K. Reiss, E. Kremmer, P. Saftig, C. Haass, Regulated intramembrane proteolysis of Bri2 (Itm2b) by ADAM10 and SPPL2a/SPPL2b, J Biol Chem 283 (2008) 1644-1652.

[70] O.A. Brady, X. Zhou, F. Hu, Regulated intramembrane proteolysis of the frontotemporal lobar degeneration risk factor, TMEM106B, by signal peptide peptidase-like 2a (SPPL2a), J Biol Chem 289 (2014) 19670-19680.

[71] D. Fleck, M. Voss, B. Brankatschk, C. Giudici, H. Hampel, B. Schwenk, D. Edbauer, A. Fukumori, H. Steiner, E. Kremmer, M. Haug-Kroper, M.J. Rossner, R. Fluhrer, M. Willem, C. Haass, Proteolytic Processing of Neuregulin 1 Type III by Three Intramembrane-cleaving Proteases, J Biol Chem 291 (2016) 318-333.

[72] A. Domonkos, A. Udvardy, L. Laszlo, T. Nagy, E. Duda, Receptor-like properties of the $26 \mathrm{kDa}$ transmembrane form of TNF, Eur Cytokine Netw 12 (2001) 411-419.

[73] R. Vidal, B. Frangione, A. Rostagno, S. Mead, T. Revesz, G. Plant, J. Ghiso, A stopcodon mutation in the BRI gene associated with familial British dementia, Nature 399 (1999) 776-781. 
[74] R. Vidal, T. Revesz, A. Rostagno, E. Kim, J.L. Holton, T. Bek, M. Bojsen-Moller, H. Braendgaard, G. Plant, J. Ghiso, B. Frangione, A decamer duplication in the 3' region of the BRI gene originates an amyloid peptide that is associated with dementia in a Danish kindred, Proc. Natl. Acad. Sci. U. S. A 97 (2000) 4920-4925.

[75] S. Matsuda, L. Giliberto, Y. Matsuda, P. Davies, E. McGowan, F. Pickford, J. Ghiso, B. Frangione, L. D'Adamio, The familial dementia BRI2 gene binds the Alzheimer gene amyloid-beta precursor protein and inhibits amyloid-beta production, J Biol Chem 280 (2005) 28912-28916.

[76] M. Tsachaki, A. Fotinopoulou, N. Slavi, V. Zarkou, J. Ghiso, S. Efthimiopoulos, BRI2 interacts with BACE1 and regulates its cellular levels by promoting its degradation and reducing its mRNA levels, Curr Alzheimer Res 10 (2013) 532-541.

[77] E. Kilger, A. Buehler, H. Woelfing, S. Kumar, S.A. Kaeser, A. Nagarathinam, J. Walter, M. Jucker, J. Coomaraswamy, BRI2 protein regulates beta-amyloid degradation by increasing levels of secreted insulin-degrading enzyme (IDE), J. Biol. Chem 286 (2011) 37446-37457.

[78] I. Noth, Y. Zhang, S.F. Ma, C. Flores, M. Barber, Y. Huang, S.M. Broderick, M.S. Wade, P. Hysi, J. Scuirba, T.J. Richards, B.M. Juan-Guardela, R. Vij, M.K. Han, F.J. Martinez, K. Kossen, S.D. Seiwert, J.D. Christie, D. Nicolae, N. Kaminski, J.G. Garcia, Genetic variants associated with idiopathic pulmonary fibrosis susceptibility and mortality: a genome-wide association study, Lancet Respir Med 1 (2013) 309-317.

[79] C. Daccord, T.M. Maher, Recent advances in understanding idiopathic pulmonary fibrosis, F1000Res 5 (2016).

[80] M. Wu, S. Assassi, G.A. Salazar, C. Pedroza, O.Y. Gorlova, W.V. Chen, J. Charles, M.L. Taing, K. Liao, F.M. Wigley, L.K. Hummers, A.A. Shah, M. Hinchcliff, D. Khanna, E. Schiopu, K. Phillips, D.E. Furst, V. Steen, M. Baron, M. Hudson, X. Zhou, J. Pope, N. Jones, P. Docherty, N.A. Khalidi, D. Robinson, R.W. Simms, R.M. Silver, T.M. Frech, B.J. Fessler, M.J. Fritzler, J.A. Molitor, B.M. Segal, M. Movahedian, J. Martin, J. Varga, M.D. Mayes, Genetic susceptibility loci of idiopathic interstitial pneumonia do not represent risk for systemic sclerosis: a case control study in Caucasian patients, Arthritis Res Ther 18 (2016) 20 .

[81] P.H. Kuhn, K. Koroniak, S. Hogl, A. Colombo, U. Zeitschel, M. Willem, C. Volbracht, U. Schepers, A. Imhof, A. Hoffmeister, C. Haass, S. Rossner, S. Brase, S.F. Lichtenthaler, Secretome protein enrichment identifies physiological BACE1 protease substrates in neurons, EMBO J 31 (2012) 3157-3168.

[82] C.E. Hamblet, S.L. Makowski, J.M. Tritapoe, J.L. Pomerantz, NK Cell Maturation and Cytotoxicity Are Controlled by the Intramembrane Aspartyl Protease SPPL3, J Immunol 196 (2016) 2614-2626.

[83] T. Tang, L. Li, J. Tang, Y. Li, W.Y. Lin, F. Martin, D. Grant, M. Solloway, L. Parker, W. Ye, W. Forrest, N. Ghilardi, T. Oravecz, K.A. Platt, D.S. Rice, G.M. Hansen, A. Abuin, D.E. Eberhart, P. Godowski, K.H. Holt, A. Peterson, B.P. Zambrowicz, F.J. de Sauvage, A mouse knockout library for secreted and transmembrane proteins, Nat Biotechnol 28 (2010) 749-755.

[84] J. Rivera, L. Tessarollo, Genetic background and the dilemma of translating mouse studies to humans, Immunity 28 (2008) 1-4. 
[85] S.L. Makowski, Z. Wang, J.L. Pomerantz, A protease-independent function for SPPL3 in NFAT activation, Mol Cell Biol 35 (2015) 451-467.

[86] M. Prakriya, R.S. Lewis, Store-Operated Calcium Channels, Physiol Rev 95 (2015) $1383-1436$.

[87] B. Schröder, P. Saftig, Intramembrane proteolysis within lysosomes, Ageing Res Rev 32 (2016) 51-64.

[88] N. Jurisch-Yaksi, R. Sannerud, W. Annaert, A fast growing spectrum of biological functions of gamma-secretase in development and disease, Biochim. Biophys. Acta 1828 (2013) 2815-2827.

[89] A. Weihofen, M.K. Lemberg, E. Friedmann, H. Rueeger, A. Schmitz, P. Paganetti, G. Rovelli, B. Martoglio, Targeting presenilin-type aspartic protease signal peptide peptidase with gamma-secretase inhibitors, J. Biol. Chem 278 (2003) 16528-16533.

[90] S. Narayanan, T. Sato, M.S. Wolfe, A C-terminal region of signal peptide peptidase defines a functional domain for intramembrane aspartic protease catalysis, J. Biol. Chem 282 (2007) 20172-20179.

[91] Y. Ran, G.Z. Ladd, C. Ceballos-Diaz, J.I. Jung, D. Greenbaum, K.M. Felsenstein, T.E. Golde, Differential Inhibition of Signal Peptide Peptidase Family Members by Established gamma-Secretase Inhibitors, PLoS One 10 (2015) e0128619.

[92] A. Weihofen, M.K. Lemberg, H.L. Ploegh, M. Bogyo, B. Martoglio, Release of signal peptide fragments into the cytosol requires cleavage in the transmembrane region by a protease activity that is specifically blocked by a novel cysteine protease inhibitor, $\mathrm{J}$ Biol Chem 275 (2000) 30951-30956.

[93] N. Gertsik, T.E. Ballard, C.W. Am Ende, D.S. Johnson, Y.M. Li, Development of CBAP-BPyne, a probe for gamma-secretase and presenilinase, Medchemcomm 5 (2014) 338341.

[94] C.J. Crump, C.W. am Ende, T.E. Ballard, N. Pozdnyakov, M. Pettersson, D.M. Chau, K.R. Bales, Y.M. Li, D.S. Johnson, Development of clickable active site-directed photoaffinity probes for gamma-secretase, Bioorg Med Chem Lett 22 (2012) 2997-3000.

[95] M.S. Shearman, D. Beher, E.E. Clarke, H.D. Lewis, T. Harrison, P. Hunt, A. Nadin, A.L. Smith, G. Stevenson, J.L. Castro, L-685,458, an aspartyl protease transition state mimic, is a potent inhibitor of amyloid beta-protein precursor gamma-secretase activity, Biochemistry 39 (2000) 8698-8704.

[96] Y.M. Li, M. Xu, M.T. Lai, Q. Huang, J.L. Castro, J. DiMuzio-Mower, T. Harrison, C. Lellis, A. Nadin, J.G. Neduvelil, R.B. Register, M.K. Sardana, M.S. Shearman, A.L. Smith, X.P. Shi, K.C. Yin, J.A. Shafer, S.J. Gardell, Photoactivated gamma-secretase inhibitors directed to the active site covalently label presenilin 1, Nature 405 (2000) 689-694.

[97] G.T. Wong, D. Manfra, F.M. Poulet, Q. Zhang, H. Josien, T. Bara, L. Engstrom, M. Pinzon-Ortiz, J.S. Fine, H.J. Lee, L. Zhang, G.A. Higgins, E.M. Parker, Chronic treatment with the gamma-secretase inhibitor LY-411,575 inhibits beta-amyloid peptide production and 
alters lymphopoiesis and intestinal cell differentiation, J. Biol. Chem 279 (2004) 1287612882.

[98] T. Otoguro, T. Tanaka, H. Kasai, A. Yamashita, K. Moriishi, Inhibitory effect of presenilin inhibitor LY411575 on maturation of hepatitis C virus core protein, production of the viral particle and expression of host proteins involved in pathogenicity, Microbiol Immunol 60 (2016) 740-753.

[99] T. Sato, K. Ananda, C.I. Cheng, E.J. Suh, S. Narayanan, M.S. Wolfe, Distinct pharmacological effects of inhibitors of signal peptide peptidase and gamma-secretase, J Biol Chem 283 (2008) 33287-33295.

[100] A.Y. Kornilova, F. Bihel, C. Das, M.S. Wolfe, The initial substrate-binding site of gamma-secretase is located on presenilin near the active site, Proc. Natl. Acad. Sci. U. S. A 102 (2005) 3230-3235.

[101] Y. Morohashi, T. Kan, Y. Tominari, H. Fuwa, Y. Okamura, N. Watanabe, C. Sato, H. Natsugari, T. Fukuyama, T. Iwatsubo, T. Tomita, C-terminal fragment of presenilin is the molecular target of a dipeptidic gamma-secretase-specific inhibitor DAPT (N-[N-(3,5difluorophenacetyl)-L-alanyl]-S-phenylglycine t-butyl ester), J. Biol. Chem 281 (2006) $14670-14676$.

[102] D. Seiffert, J.D. Bradley, C.M. Rominger, D.H. Rominger, F. Yang, J.E. Meredith, Jr., Q. Wang, A.H. Roach, L.A. Thompson, S.M. Spitz, J.N. Higaki, S.R. Prakash, A.P. Combs, R.A. Copeland, S.P. Arneric, P.R. Hartig, D.W. Robertson, B. Cordell, A.M. Stern, R.E. Olson, R. Zaczek, Presenilin-1 and -2 are molecular targets for gamma-secretase inhibitors, J Biol Chem 275 (2000) 34086-34091.

[103] J. Milano, J. McKay, C. Dagenais, L. Foster-Brown, F. Pognan, R. Gadient, R.T. Jacobs, A. Zacco, B. Greenberg, P.J. Ciaccio, Modulation of notch processing by gammasecretase inhibitors causes intestinal goblet cell metaplasia and induction of genes known to specify gut secretory lineage differentiation, Toxicol Sci 82 (2004) 341-358.

[104] N. Gertsik, D.M. Chau, Y.M. Li, gamma-Secretase Inhibitors and Modulators Induce Distinct Conformational Changes in the Active Sites of gamma-Secretase and Signal Peptide Peptidase, ACS Chem Biol 10 (2015) 1925-1931.

[105] K.W. Gillman, J.E. Starrett, Jr., M.F. Parker, K. Xie, J.J. Bronson, L.R. Marcin, K.E. McElhone, C.P. Bergstrom, R.A. Mate, R. Williams, J.E. Meredith, Jr., C.R. Burton, D.M. Barten, J.H. Toyn, S.B. Roberts, K.A. Lentz, J.G. Houston, R. Zaczek, C.F. Albright, C.P. Decicco, J.E. Macor, R.E. Olson, Discovery and Evaluation of BMS-708163, a Potent, Selective and Orally Bioavailable gamma-Secretase Inhibitor, ACS Med Chem Lett 1 (2010) $120-124$.

[106] D.B. Henley, P.C. May, R.A. Dean, E.R. Siemers, Development of semagacestat (LY450139), a functional gamma-secretase inhibitor, for the treatment of Alzheimer's disease, Expert Opin Pharmacother 10 (2009) 1657-1664.

[107] X.C. Bai, C. Yan, G. Yang, P. Lu, D. Ma, L. Sun, R. Zhou, S.H. Scheres, Y. Shi, An atomic structure of human gamma-secretase, Nature 525 (2015) 212-217.

[108] S.J. Bray, Notch signalling in context, Nat Rev Mol Cell Biol 17 (2016) 722-735. 
[109] P. Rizzo, C. Osipo, K. Foreman, T. Golde, B. Osborne, L. Miele, Rational targeting of Notch signaling in cancer, Oncogene 27 (2008) 5124-5131.

[110] B. De Strooper, P. Saftig, K. Craessaerts, H. Vanderstichele, G. Guhde, W. Annaert, K. von Figura, F. Van Leuven, Deficiency of presenilin-1 inhibits the normal cleavage of amyloid precursor protein, Nature 391 (1998) 387-390.

[111] T.E. Golde, E.H. Koo, K.M. Felsenstein, B.A. Osborne, L. Miele, gamma-Secretase inhibitors and modulators, Biochim Biophys Acta 1828 (2013) 2898-2907.

[112] R.S. Doody, R. Raman, M. Farlow, T. Iwatsubo, B. Vellas, S. Joffe, K. Kieburtz, F. He, X. Sun, R.G. Thomas, P.S. Aisen, E. Siemers, G. Sethuraman, R. Mohs, A phase 3 trial of semagacestat for treatment of Alzheimer's disease, N. Engl. J. Med 369 (2013) 341-350.

[113] I. Krop, T. Demuth, T. Guthrie, P.Y. Wen, W.P. Mason, P. Chinnaiyan, N. Butowski, M.D. Groves, S. Kesari, S.J. Freedman, S. Blackman, J. Watters, A. Loboda, A. Podtelezhnikov, J. Lunceford, C. Chen, M. Giannotti, J. Hing, R. Beckman, P. Lorusso, Phase I pharmacologic and pharmacodynamic study of the gamma secretase (Notch) inhibitor MK0752 in adult patients with advanced solid tumors, J Clin Oncol 30 (2012) 2307-2313.

[114] E.A. Kolb, R. Gorlick, S.T. Keir, J.M. Maris, R. Lock, H. Carol, R.T. Kurmasheva, C.P. Reynolds, M.H. Kang, J. Wu, P.J. Houghton, M.A. Smith, Initial testing (stage 1) by the pediatric preclinical testing program of RO4929097, a gamma-secretase inhibitor targeting notch signaling, Pediatr Blood Cancer 58 (2012) 815-818.

[115] J.R. Strosberg, T. Yeatman, J. Weber, D. Coppola, M.J. Schell, G. Han, K. Almhanna, R. Kim, T. Valone, H. Jump, D. Sullivan, A phase II study of RO4929097 in metastatic colorectal cancer, Eur J Cancer 48 (2012) 997-1003.

[116] B. De Strooper, Lessons from a failed gamma-secretase Alzheimer trial, Cell 159 (2014) 721-726.

[117] B. De Strooper, L. Chavez Gutierrez, Learning by failing: ideas and concepts to tackle gamma-secretases in Alzheimer's disease and beyond, Annu. Rev. Pharmacol. Toxicol 55 (2015) 419-437.

[118] Y. Mitani, J. Yarimizu, K. Saita, H. Uchino, H. Akashiba, Y. Shitaka, K. Ni, N. Matsuoka, Differential effects between gamma-secretase inhibitors and modulators on cognitive function in amyloid precursor protein-transgenic and nontransgenic mice, J. Neurosci 32 (2012) 2037-2050.

[119] J. McLauchlan, M.K. Lemberg, G. Hope, B. Martoglio, Intramembrane proteolysis promotes trafficking of hepatitis C virus core protein to lipid droplets, EMBO J 21 (2002) 3980-3988.

[120] T. Tanaka, H. Kasai, A. Yamashita, K. Okuyama-Dobashi, J. Yasumoto, S. Maekawa, N. Enomoto, T. Okamoto, Y. Matsuura, M. Morimatsu, N. Manabe, K. Ochiai, K. Yamashita, K. Moriishi, Hallmarks of hepatitis C virus in equine hepacivirus, J Virol 88 (2014) 1335213366.

[121] D. Moradpour, A. Grakoui, M.P. Manns, Future landscape of hepatitis C research Basic, translational and clinical perspectives, J Hepatol 65 (2016) S143-155. 
[122] C.C. Kao, G. Yi, H.C. Huang, The core of hepatitis C virus pathogenesis, Curr Opin Virol 17 (2016) 66-73.

[123] P. Hussy, H. Langen, J. Mous, H. Jacobsen, Hepatitis C virus core protein: carboxyterminal boundaries of two processed species suggest cleavage by a signal peptide peptidase, Virology 224 (1996) 93-104.

[124] V. Pene, C. Hernandez, C. Vauloup-Fellous, J. Garaud-Aunis, A.R. Rosenberg, Sequential processing of hepatitis $\mathrm{C}$ virus core protein by host cell signal peptidase and signal peptide peptidase: a reassessment, J Viral Hepat 16 (2009) 705-715.

[125] M. Ait-Goughoulte, C. Hourioux, R. Patient, S. Trassard, D. Brand, P. Roingeard, Core protein cleavage by signal peptide peptidase is required for hepatitis $\mathrm{C}$ virus-like particle assembly, J. Gen. Virol 87 (2006) 855-860.

[126] K. Okamoto, K. Moriishi, T. Miyamura, Y. Matsuura, Intramembrane proteolysis and endoplasmic reticulum retention of hepatitis C virus core protein, J. Virol 78 (2004) 63706380 .

[127] R.G. Hope, M.J. McElwee, J. McLauchlan, Efficient cleavage by signal peptide peptidase requires residues within the signal peptide between the core and E1 proteins of hepatitis C virus strain J1, J. Gen. Virol 87 (2006) 623-627.

[128] K. Okamoto, Y. Mori, Y. Komoda, T. Okamoto, M. Okochi, M. Takeda, T. Suzuki, K. Moriishi, Y. Matsuura, Intramembrane processing by signal peptide peptidase regulates the membrane localization of hepatitis $\mathrm{C}$ virus core protein and viral propagation, J. Virol 82 (2008) 8349-8361.

[129] G. Randall, M. Panis, J.D. Cooper, T.L. Tellinghuisen, K.E. Sukhodolets, S. Pfeffer, M. Landthaler, P. Landgraf, S. Kan, B.D. Lindenbach, M. Chien, D.B. Weir, J.J. Russo, J. Ju, M.J. Brownstein, R. Sheridan, C. Sander, M. Zavolan, T. Tuschl, C.M. Rice, Cellular cofactors affecting hepatitis C virus infection and replication, Proc Natl Acad Sci U S A 104 (2007) 12884-12889.

[130] E. Billerbeck, Y. de Jong, M. Dorner, C. de la Fuente, A. Ploss, Animal models for hepatitis C, Curr Top Microbiol Immunol 369 (2013) 49-86.

[131] M. Heimann, G. Roman-Sosa, B. Martoglio, H.J. Thiel, T. Rumenapf, Core protein of pestiviruses is processed at the $\mathrm{C}$ terminus by signal peptide peptidase, J. Virol 80 (2006) 1915-1921.

[132] X. Shi, C.H. Botting, P. Li, M. Niglas, B. Brennan, S.L. Shirran, A.M. Szemiel, R.M. Elliott, Bunyamwera orthobunyavirus glycoprotein precursor is processed by cellular signal peptidase and signal peptide peptidase, Proc Natl Acad Sci U S A 113 (2016) 8825-8830.

[133] S.J. Allen, K.R. Mott, Y. Matsuura, K. Moriishi, K.G. Kousoulas, H. Ghiasi, Binding of HSV-1 glycoprotein $\mathrm{K}(\mathrm{gK})$ to signal peptide peptidase (SPP) is required for virus infectivity, PLoS One 9 (2014) e85360.

[134] S.J. Allen, K.R. Mott, H. Ghiasi, Inhibitors of signal peptide peptidase (SPP) affect HSV-1 infectivity in vitro and in vivo, Exp Eye Res 123 (2014) 8-15. 
[135] J. Loureiro, B.N. Lilley, E. Spooner, V. Noriega, D. Tortorella, H.L. Ploegh, Signal peptide peptidase is required for dislocation from the endoplasmic reticulum, Nature 441 (2006) 894-897.

[136] R.T. Gazzinelli, P. Kalantari, K.A. Fitzgerald, D.T. Golenbock, Innate sensing of malaria parasites, Nat Rev Immunol 14 (2014) 744-757.

[137] A.C. Nyborg, T.B. Ladd, K. Jansen, T. Kukar, T.E. Golde, Intramembrane proteolytic cleavage by human signal peptide peptidase like 3 and malaria signal peptide peptidase, FASEB J 20 (2006) 1671-1679.

[138] M. Baldwin, C. Russo, X. Li, A.H. Chishti, Plasmodium falciparum signal peptide peptidase cleaves malaria heat shock protein 101 (HSP101). Implications for gametocytogenesis, Biochem Biophys Res Commun 450 (2014) 1427-1432.

[139] D.S. Marapana, D.W. Wilson, E.S. Zuccala, C.D. Dekiwadia, J.G. Beeson, S.A. Ralph, J. Baum, Malaria parasite signal peptide peptidase is an ER-resident protease required for growth but not for invasion, Traffic 13 (2012) 1457-1465.

[140] M.B. Harbut, B.A. Patel, B.K. Yeung, C.W. McNamara, A.T. Bright, J. Ballard, F. Supek, T.E. Golde, E.A. Winzeler, T.T. Diagana, D.C. Greenbaum, Targeting the ERAD pathway via inhibition of signal peptide peptidase for antiparasitic therapeutic design, Proc Natl Acad Sci U S A 109 (2012) 21486-21491.

[141] X. Li, H. Chen, N. Bahamontes-Rosa, J.F. Kun, B. Traore, P.D. Crompton, A.H. Chishti, Plasmodium falciparum signal peptide peptidase is a promising drug target against blood stage malaria, Biochem. Biophys. Res. Commun 380 (2009) 454-459.

[142] I. Parvanova, S. Epiphanio, A. Fauq, T.E. Golde, M. Prudencio, M.M. Mota, A small molecule inhibitor of signal Peptide peptidase inhibits Plasmodium development in the liver and decreases malaria severity, PLoS. ONE 4 (2009) e5078.

[143] WHO Malaria Report, 2016.

[144] S. Hüttl, K. Klasener, M. Schweizer, J. Schneppenheim, H.H. Oberg, D. Kabelitz, M. Reth, P. Saftig, B. Schröder, Processing of CD74 by the Intramembrane Protease SPPL2a Is Critical for B Cell Receptor Signaling in Transitional B Cells, J Immunol 195 (2015) 15481563.

[145] D.J. Rawlings, G. Metzler, M. Wray-Dutra, S.W. Jackson, Altered B cell signalling in autoimmunity, Nat Rev Immunol (2017).

[146] C. Audiger, M.J. Rahman, T.J. Yun, K.V. Tarbell, S. Lesage, The Importance of Dendritic Cells in Maintaining Immune Tolerance, J Immunol 198 (2017) 2223-2231.

[147] G. Faure-Andre, P. Vargas, M.I. Yuseff, M. Heuze, J. Diaz, D. Lankar, V. Steri, J. Manry, S. Hugues, F. Vascotto, J. Boulanger, G. Raposo, M.R. Bono, M. Rosemblatt, M. Piel, A.M. Lennon-Dumenil, Regulation of dendritic cell migration by CD74, the MHC class IIassociated invariant chain, Science 322 (2008) 1705-1710.

[148] L.N. Adler, W. Jiang, K. Bhamidipati, M. Millican, C. Macaubas, S.C. Hung, E.D. Mellins, The Other Function: Class II-Restricted Antigen Presentation by B Cells, Front Immunol 8 (2017) 319. 
[149] O.T. Chan, L.G. Hannum, A.M. Haberman, M.P. Madaio, M.J. Shlomchik, A novel mouse with B cells but lacking serum antibody reveals an antibody-independent role for B cells in murine lupus, J Exp Med 189 (1999) 1639-1648.

[150] W.F. Pendergraft, 3rd, F.B. Cortazar, J. Wenger, A.P. Murphy, E.P. Rhee, K.A. Laliberte, J.L. Niles, Long-term maintenance therapy using rituximab-induced continuous Bcell depletion in patients with ANCA vasculitis, Clin J Am Soc Nephrol 9 (2014) 736-744.

[151] D. Cornec, J. Avouac, P. Youinou, A. Saraux, Critical analysis of rituximab-induced serological changes in connective tissue diseases, Autoimmun Rev 8 (2009) 515-519.

[152] B. Terrier, Z. Amoura, P. Ravaud, E. Hachulla, R. Jouenne, B. Combe, C. Bonnet, P. Cacoub, A. Cantagrel, M. de Bandt, O. Fain, B. Fautrel, P. Gaudin, B. Godeau, J.R. Harle, A. Hot, J.E. Kahn, O. Lambotte, C. Larroche, J. Leone, O. Meyer, B. Pallot-Prades, E. Pertuiset, P. Quartier, T. Schaerverbeke, J. Sibilia, A. Somogyi, M. Soubrier, E. Vignon, B. BaderMeunier, X. Mariette, J.E. Gottenberg, I. Club Rhumatismes et, Safety and efficacy of rituximab in systemic lupus erythematosus: results from 136 patients from the French AutoImmunity and Rituximab registry, Arthritis Rheum 62 (2010) 2458-2466.

[153] J.C. Edwards, L. Szczepanski, J. Szechinski, A. Filipowicz-Sosnowska, P. Emery, D.R. Close, R.M. Stevens, T. Shaw, Efficacy of B-cell-targeted therapy with rituximab in patients with rheumatoid arthritis, N Engl J Med 350 (2004) 2572-2581.

[154] J.H. Stone, P.A. Merkel, R. Spiera, P. Seo, C.A. Langford, G.S. Hoffman, C.G. Kallenberg, E.W. St Clair, A. Turkiewicz, N.K. Tchao, L. Webber, L. Ding, L.P. Sejismundo, K. Mieras, D. Weitzenkamp, D. Ikle, V. Seyfert-Margolis, M. Mueller, P. Brunetta, N.B. Allen, F.C. Fervenza, D. Geetha, K.A. Keogh, E.Y. Kissin, P.A. Monach, T. Peikert, C. Stegeman, S.R. Ytterberg, U. Specks, R.-I.R. Group, Rituximab versus cyclophosphamide for ANCA-associated vasculitis, N Engl J Med 363 (2010) 221-232.

[155] K. Dahan, H. Debiec, E. Plaisier, M. Cachanado, A. Rousseau, L. Wakselman, P.A. Michel, F. Mihout, B. Dussol, M. Matignon, C. Mousson, T. Simon, P. Ronco, G.S. Group, Rituximab for Severe Membranous Nephropathy: A 6-Month Trial with Extended Follow-Up, J Am Soc Nephrol 28 (2017) 348-358.

[156] A.R. Ahmed, Z. Spigelman, L.A. Cavacini, M.R. Posner, Treatment of pemphigus vulgaris with rituximab and intravenous immune globulin, N Engl J Med 355 (2006) 17721779 .

[157] S.L. Hauser, E. Waubant, D.L. Arnold, T. Vollmer, J. Antel, R.J. Fox, A. Bar-Or, M. Panzara, N. Sarkar, S. Agarwal, A. Langer-Gould, C.H. Smith, H.T. Group, B-cell depletion with rituximab in relapsing-remitting multiple sclerosis, N Engl J Med 358 (2008) 676-688.

[158] A. Poggi, M.R. Zocchi, NK cell autoreactivity and autoimmune diseases, Front Immunol 5 (2014) 27.

[159] H.F. Dovey, V. John, J.P. Anderson, L.Z. Chen, A.P. de Saint, L.Y. Fang, S.B. Freedman, B. Folmer, E. Goldbach, E.J. Holsztynska, K.L. Hu, K.L. Johnson-Wood, S.L. Kennedy, D. Kholodenko, J.E. Knops, L.H. Latimer, M. Lee, Z. Liao, I.M. Lieberburg, R.N. Motter, L.C. Mutter, J. Nietz, K.P. Quinn, K.L. Sacchi, P.A. Seubert, G.M. Shopp, E.D. Thorsett, J.S. Tung, J. Wu, S. Yang, C.T. Yin, D.B. Schenk, P.C. May, L.D. Altstiel, M.H. Bender, L.N. Boggs, T.C. Britton, J.C. Clemens, D.L. Czilli, D.K. Dieckman-McGinty, J.J. 
Droste, K.S. Fuson, B.D. Gitter, P.A. Hyslop, E.M. Johnstone, W.Y. Li, S.P. Little, T.E. Mabry, F.D. Miller, J.E. Audia, Functional gamma-secretase inhibitors reduce beta-amyloid peptide levels in brain, J. Neurochem 76 (2001) 173-181.

[160] M.S. Wolfe, M. Citron, T.S. Diehl, W. Xia, I.O. Donkor, D.J. Selkoe, A substrate-based difluoro ketone selectively inhibits Alzheimer's gamma-secretase activity, J Med Chem 41 (1998) 6-9.

[161] L. Luistro, W. He, M. Smith, K. Packman, M. Vilenchik, D. Carvajal, J. Roberts, J. Cai, W. Berkofsky-Fessler, H. Hilton, M. Linn, A. Flohr, R. Jakob-Rotne, H. Jacobsen, K. Glenn, D. Heimbrook, J.F. Boylan, Preclinical profile of a potent gamma-secretase inhibitor targeting notch signaling with in vivo efficacy and pharmacodynamic properties, Cancer Res 69 (2009) $7672-7680$

[162] R.E. Olson, C.F. Albright, Recent progress in the medicinal chemistry of gammasecretase inhibitors, Curr Top Med Chem 8 (2008) 17-33. 
TABLES

Table 1. Reported phenotypes of SPP/SPPL knockout mice

\begin{tabular}{|c|c|c|c|c|}
\hline I-CLIP & Knockout & Phenotype & $\begin{array}{l}\text { Involved } \\
\text { Substrates }\end{array}$ & Reference \\
\hline SPP & Constitutive & Embryonic lethality & Unknown & {$[51]$} \\
\hline \multirow{3}{*}{ SPPL2a } & \multirow{3}{*}{ Constitutive } & Arrest of splenic B cell maturation & CD74 & {$[29,58,59]$} \\
\hline & & Reduction of dendritic cells & $\mathrm{CD} 74$ & [58-60] \\
\hline & & Tooth enamel mineralisation defect & Not known & {$[68]$} \\
\hline SPPL2b & Constitutive & Viable, no specific phenotype reported yet. & & {$[60]$} \\
\hline \multirow{3}{*}{$\begin{array}{l}\text { SPPL2a/ } \\
\text { SPPL2b }\end{array}$} & \multirow{3}{*}{ Constitutive } & Arrest of splenic B cell maturation & CD74 & {$[60]$} \\
\hline & & Reduction of dendritic cells & $\mathrm{CD} 74$ & {$[60]$} \\
\hline & & Tooth enamel mineralisation defect & Not known & {$[60]$} \\
\hline SPPL2c & & Not reported yet & - & - \\
\hline \multirow{6}{*}{ SPPL3 } & $\begin{array}{l}\text { Constitutive } \\
\text { (C57/B16 J) }\end{array}$ & Perinatal lethality & Not known & {$[82]$} \\
\hline & \multirow{3}{*}{$\begin{array}{l}\text { Constitutive } \\
\text { (C57BL/6;129S5) }\end{array}$} & Viable, growth retardation & Not known & [83] \\
\hline & & Reduction of NK cells & Not known & {$[83]$} \\
\hline & & Male sterility & Not known & {$[83]$} \\
\hline & $\begin{array}{l}\text { Hematopoetic cells } \\
(\text { Vav } 1-i C r e)\end{array}$ & Impaired NK cell maturation and function & Not known & {$[82]$} \\
\hline & $\begin{array}{l}\text { NK cells } \\
(\mathrm{NKp} 46-i \mathrm{Cre})\end{array}$ & Impaired NK cell maturation and function & Not known & {$[82]$} \\
\hline
\end{tabular}


Table 2. Inhibitory profile of different GxGD-type proteases.

\begin{tabular}{|c|c|c|c|c|c|c|c|}
\hline & m/hSPP & PfSPP & SPPL2a & SPPL2b & SPPL2c & SPPL3 & $\gamma$-secretase \\
\hline$(\mathrm{Z}-\mathbf{L L})_{2}$-ketone & $+[89,92]$ & $+[137,138]$ & $+\quad[47]$ & $+[4,47]$ & No data & - $[6]$ & $\begin{array}{ll}- & {[89]}\end{array}$ \\
\hline L-685,458 & $+\quad[89]$ & [138] & $+\quad[47]$ & $+\quad[47]$ & No data & - $\quad[6]$ & $+\quad[95]$ \\
\hline LY-411,575 & $+\quad[22]$ & [137] & $+\quad[91]$ & $+[91]$ & No data & No data & $+\quad[97]$ \\
\hline DAPT & $-\quad[22]$ & [138] & $\begin{array}{ll}- & {[91]}\end{array}$ & $-[6,91]$ & No data & $\begin{array}{ll}- & {[6]}\end{array}$ & $+\quad[159]$ \\
\hline DBZ & $+\quad(91)$ & (91) & $\pm \quad(91)$ & - $\quad(91)$ & No data & No data & $+\quad(158)$ \\
\hline GSI II & $+\quad(91)$ & (91) & $+\quad(91)$ & $+\quad(91)$ & No data & No data & $+\quad[160]$ \\
\hline RO4929097 & $+[51]$ & No data & No data & No data & No data & No data & $+\quad[161]$ \\
\hline Semagecestat & $-\quad[51]$ & No data & No data & No data & No data & No data & $+[106]$ \\
\hline Avagecestat & $-\quad[51]$ & No data & No data & No data & No data & No data & $+[105]$ \\
\hline MK-0752 & $-\quad[51]$ & No data & No data & No data & No data & No data & $+\quad[162]$ \\
\hline Compound E & ? $\quad[22,91]$ & [91] & $\pm \quad[91]$ & - $\quad[91]$ & No data & No data & $+\quad[102]$ \\
\hline
\end{tabular}

$+:$ Inhibition ; -: No effect of inhibitor; \pm : Weak effects; ? Conflicting reports; 


\section{FIGURE LEGENDS}

Fig.1: Comparison of SPP/SPPLs and $\gamma$-secretase. Even though sharing highly conserved catalytic motifs in transmembrane domains 6, 7 and 9, SPP/SPPL proteases greatly differ from $\gamma$-secretase. While $\gamma$-secretase requires the formation of a heterotetrameric complex consisting of Aph1, Pen2, Nicastrin and the catalytic presenilin subunits for its activity, SPP/SPPL proteases either act as mono- or homodimers. Furthermore, SPP/SPPL proteases present an inverted topology if compared to the presenilins which is also reflected by the differential requirements regarding substrate orientation in either type II or type I topology, respectively.

Fig. 2. Known inhibitors of SPP/SPPL proteases. Chemical structures of the so far only available selective SPP/SPPL family inhibitor (Z-LL)2-ketone and the mixed $\gamma$ secretase/SPP/SPPL inhibitors L-685,458, LY-411575 and Compound E are depicted. For comparison, structures of the selective $\gamma$-secretase inhibitors DAPT and Semagecestat are displayed. Structures were drawn using ChemSketch software.

Fig. 3. Scheme for potential applications of SPP inhibitors. A Inhibitors targeting SPP might be applied for treatment of HCV infections based on the requirement for SPP for the processing of the immature HCV core protein. Pharmacological targeting of endogenous SPP inhibits cleavage of the immature HCV core protein thereby preventing its transport to lipid droplets and therefore also viral assembly and propagation. B Inhibition of Plasmodium SPP (P1SPP) could be of clinical relevance for fighting malaria infections. Even though the precise mechanism underlying toxicity of SPP inhibitors for Plasmodium still remains enigmatic, 
blocked SPP-mediated proteolysis might cause ER stress leading to an altered Plasmodium life cycle and growth inhibition.

Fig. 4. Scheme for potential applications of SPPL2a inhibitors. SPPL2a inhibitors may be of use for treatment of B cell-mediated autoimmune disease. Blocking SPPL2a activity leads to endolysosomal accumulation of the CD74 N-terminal fragment (NTF), thereby disturbing vesicular membrane trafficking. Increased levels of this fragment also cause intracellular sequestration of B cell receptors as well as downregulation of BAFF receptors on the surface of B cells. Furthermore, by a yet unknown mechanism, the accumulating CD74 NTF decreases tonic and induced survival signalling downstream of the BCR leading to a maturation arrest in the early splenic T1 stage. 
Figure 1

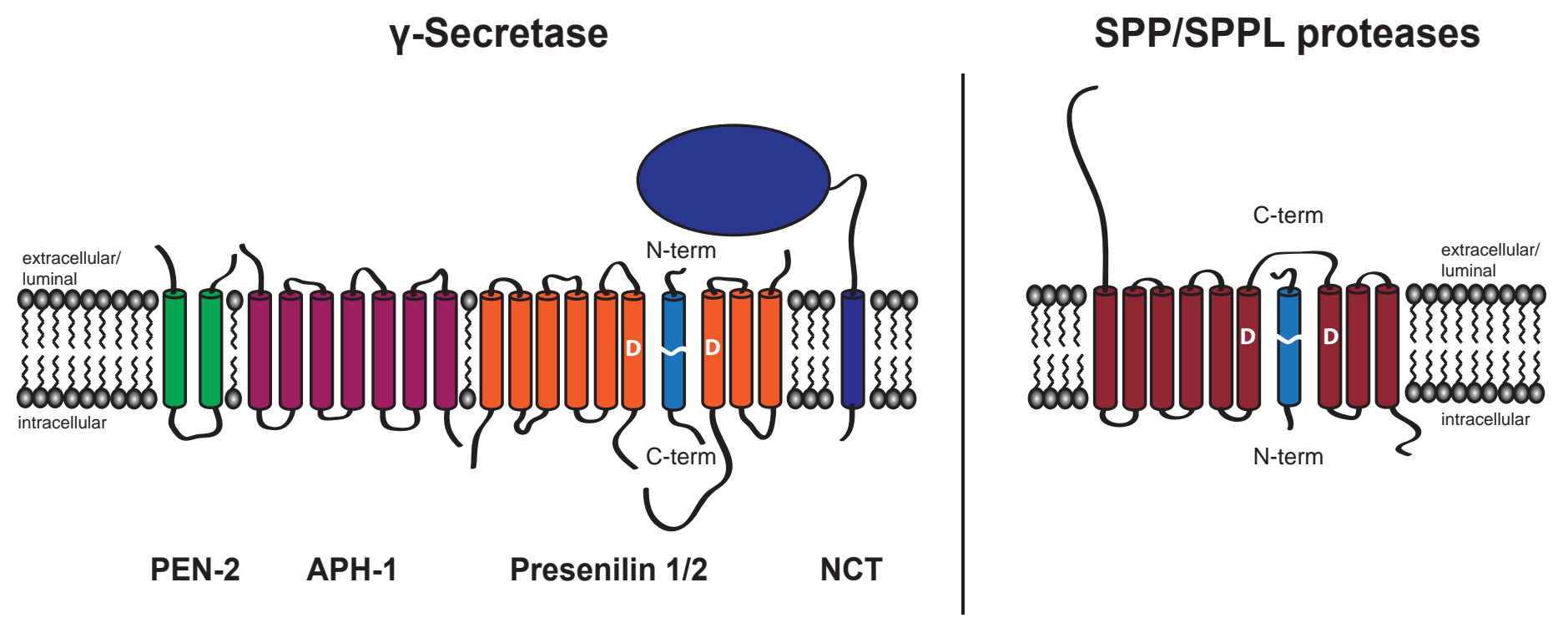


Figure 2

(Z-LL) $)_{2}$-ketone

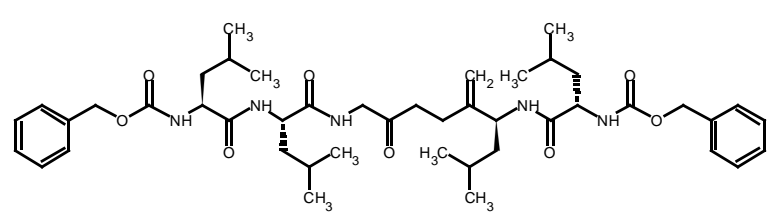

Compound E

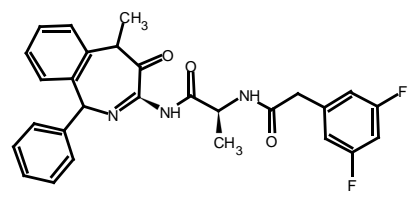

L-685,458

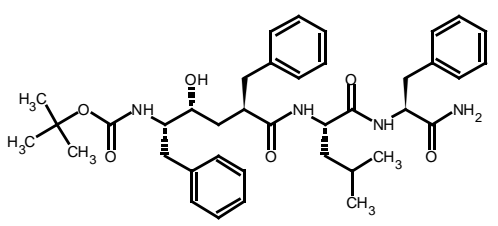

DAPT

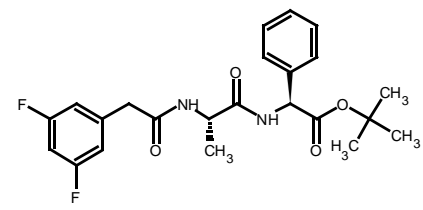

LY-411575

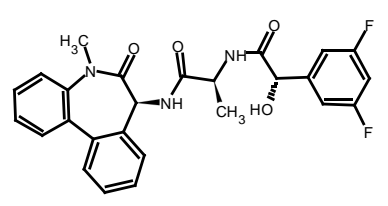

Semagecestat

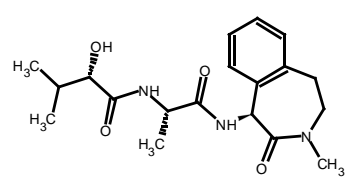


Figure 3

A

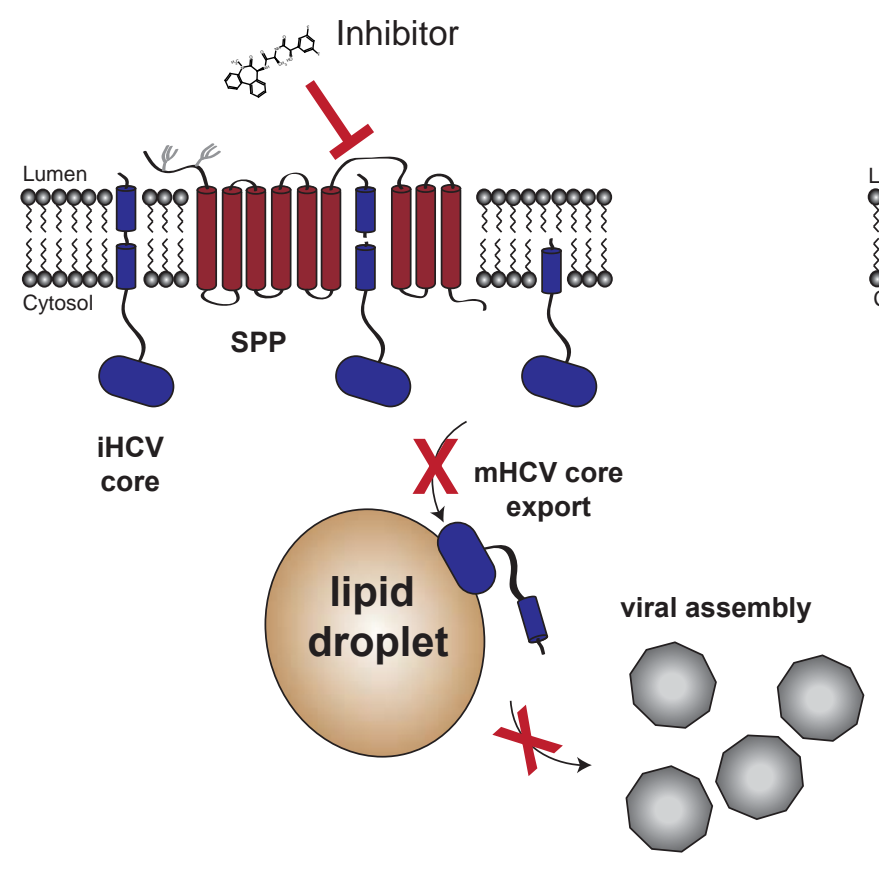

B

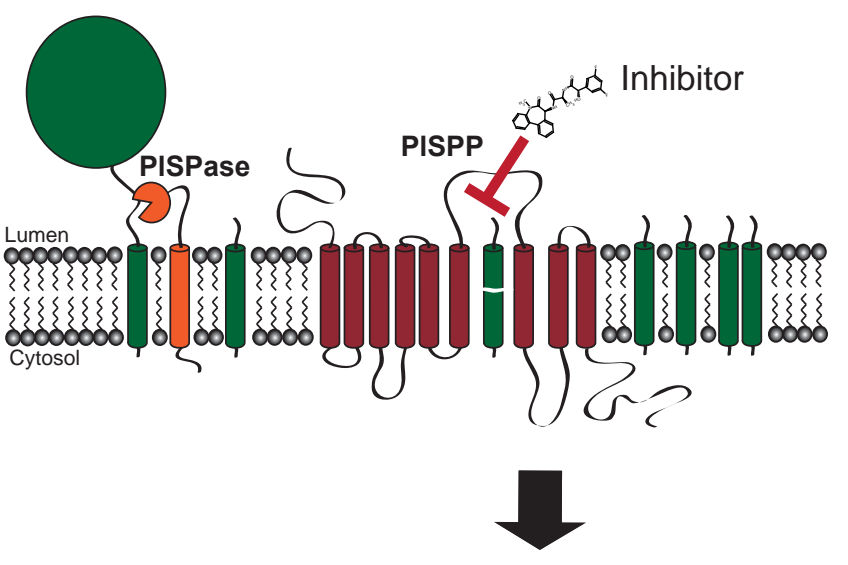

ER stress induction

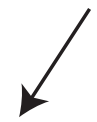

altered growth less

life cycle inhibition invasion? 
Figure 4

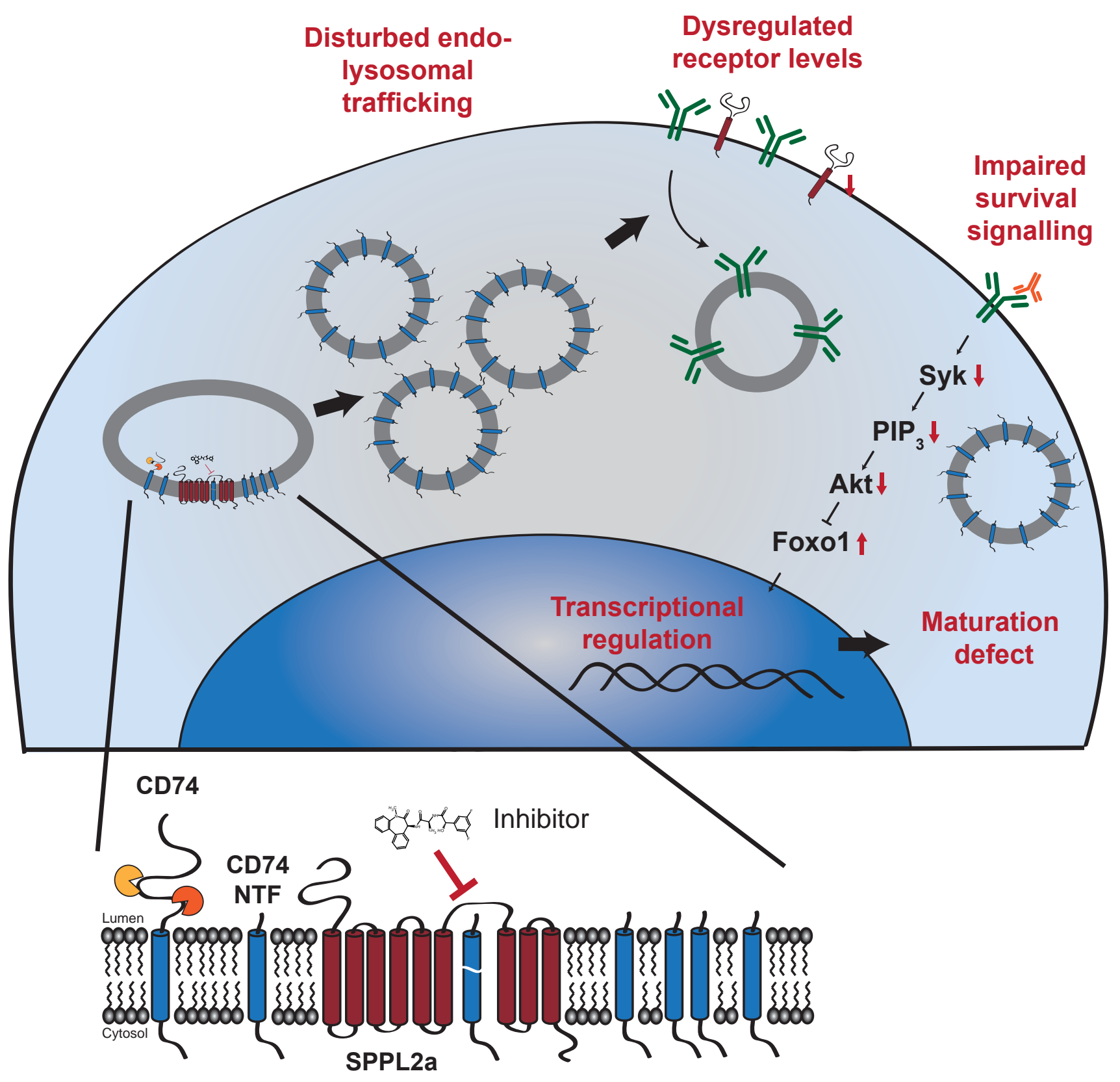

